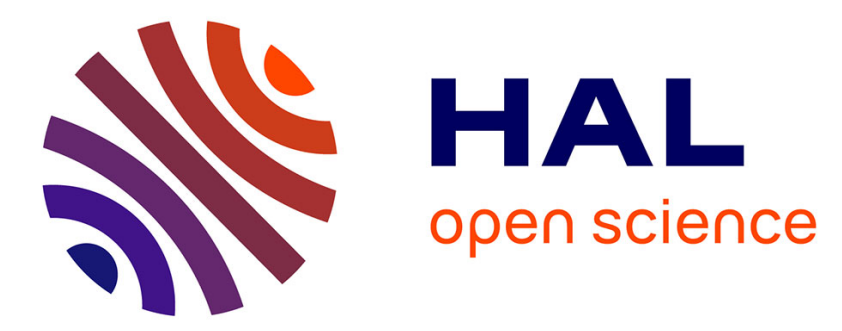

\title{
Study of the hot forging of weld cladded work pieces using upsetting tests
}

\author{
Jingcai Wang, Laurent Langlois, Muhammad Rafiq, Régis Bigot, Hao Lu
}

\section{To cite this version:}

Jingcai Wang, Laurent Langlois, Muhammad Rafiq, Régis Bigot, Hao Lu. Study of the hot forging of weld cladded work pieces using upsetting tests. Journal of Materials Processing Technology, 2014, 214 (2), pp.365-379. 10.1016/j.jmatprotec.2013.09.009 . hal-01097259

\section{HAL Id: hal-01097259 \\ https://hal.science/hal-01097259}

Submitted on 7 Jan 2015

HAL is a multi-disciplinary open access archive for the deposit and dissemination of scientific research documents, whether they are published or not. The documents may come from teaching and research institutions in France or abroad, or from public or private research centers.
L'archive ouverte pluridisciplinaire HAL, est destinée au dépôt et à la diffusion de documents scientifiques de niveau recherche, publiés ou non, émanant des établissements d'enseignement et de recherche français ou étrangers, des laboratoires publics ou privés. 


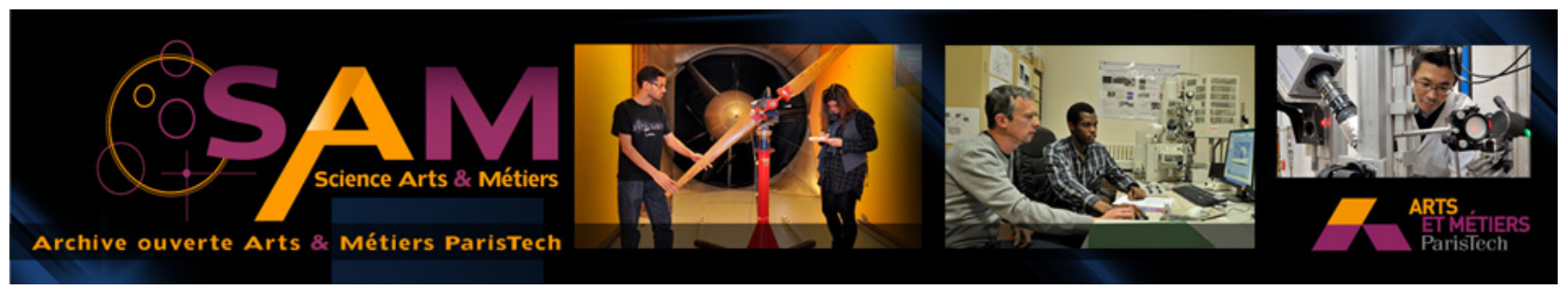

Science Arts \& Métiers (SAM)

is an open access repository that collects the work of Arts et Métiers ParisTech researchers and makes it freely available over the web where possible.

This is an author-deposited version published in: http://sam.ensam.eu Handle ID: .http://hdl.handle.net/10985/9130

\section{To cite this version :}

Jingcai WANG, Laurent LANGLOIS, Muhammad RAFIQ, Régis BIGOT, Hao LU - Study of the hot forging of weld cladded work pieces using upsetting tests - Journal of Materials Processing Technology - Vol. 214, n², p.365-379 - 2014 


\title{
Study of the hot forging of weld cladded work pieces using upsetting tests
}

\author{
Jingcai Wang ${ }^{\mathrm{a}, \mathrm{b}}$, Laurent Langlois ${ }^{\mathrm{a}, *}$, Muhammad Rafiq $^{\mathrm{a}}$, Régis Bigot ${ }^{\mathrm{a}}, \mathrm{Hao} \mathrm{Lu}^{\mathrm{b}}$ \\ a LCFC, ParisTech, 4 rue Augustin Fresnel, 57070 Metz, France \\ ${ }^{\mathrm{b}}$ Welding Engineering Institute of Shanghai Jiao Tong University, 200240 Shanghai, China
}

Keywords:

Multi-material

Forgeability

Stainless steel

Weld cladding
This paper focuses on the hot forging of multi-material cladded work pieces using upsetting tests. The case study corresponds to gas metal arc welding cladding of a SS316L on a mild steel (C15). Experimental tests and simulations using a slab model and the finite element method were performed using different temperatures and die/billet tribological conditions. As a result, a crack mode, specific to clad billets, was observed experimentally and can be predicted by the FE method using a Latham and Cockcroft criterion. The material distribution was well simulated by the FE method; in particular, the effects of the friction at die/work piece interface on the crack occurrence, the material distribution and, to a lesser extent, the forging load are well predicted. However, the latter was underestimated, highlighting the fact that the effect of the dilution associated with the cladding process on the material behavior of the clad layer cannot be neglected.

\section{Introduction}

The ability to achieve various mechanical and metallurgical properties is the main driving forces in the selection of many manufacturing processes. In the classical fabrication of cladded products, hot forging process is normally performed before cladding which induces problems of low efficiency and bad quality control. It is considered that these problems might be reduced by changing the order of the two processes (see Fig. 1) where a simple preform is cladded and then forged to obtain a complex shape. Due to the ease of automation of the cladding process for simple shapes, good control on cladding quality can be achieved. The final metallurgical structure of the clad layer is then the result of hot working instead of solidification.

The objective of this study is to analyze the ability of a cladded work piece under hot forging to obtain a defect-free material distribution and structure. However, it must be considered that the forgeability of the bi-material cladded work piece is heterogeneous; the ductility of the cladding layer is unknown as it is a mixture of the substrate metal and filler material depending on the dilution rate and is likely influenced by conditions that exist during hot forming.

The interface between the substrate and the clad layer depends on the cladding process. The cladding considered in this study is the

\footnotetext{
* Corresponding author. Tel.: +33 387375456 .

E-mail address: laurent.langlois@ensam.eu (L. Langlois).
}

gas metal arc welding (GMAW) cladding process which exhibits a wavy morphology. The interface defects and local geometrical effects can also have a great influence on the ductility of the cladded work piece. Besides, it can be difficult to control the distribution of materials during hot forming.

Due to the difference in rheological properties at different positions of the cladded work piece, a characterization of the forgeability on three levels is proposed (see Fig. 2):

Level 1: The intrinsic forgeability of the materials constituting the substrate and the clad layer. The intrinsic forgeability concerns the flow stress depending on the thermo mechanical parameters (temperature, plastic strain and plastic strain rate) and the ductility limit. This level of forgeability depends on the chemical composition and microstructure of the material.

Level 2: This level of forgeability concerns two aspects:

o the ability of the interface between the substrate and the cladding to undergo the thermo mechanical loading generated during forming,

o the interface can exhibit a wavy morphology in the case of a stepby-step cladding process like laser cladding (Cao et al., 2008). To this morphology can correspond a heterogeneous cladding thickness with associated stress concentration leading to strain localization and early cracking.

Level 3: This level of forgeability concerns the difficulties to achieve the required material distribution at the end of the forming process. The location of the cladding on the initial billet has to 


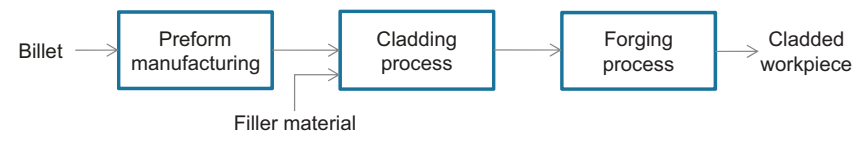

Fig. 1. Studied manufacturing layout consisting of a cladding process and a subsequent forging process.

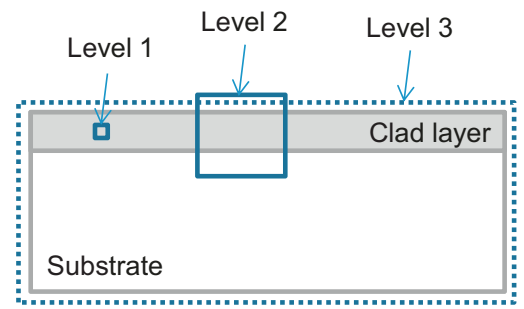

Fig. 2. Characterization approach for bi-material cladded workpiece.

be chosen carefully in order to obtain after forming the requisite material distribution within the final part. Due to the difference between the forming behavior of the substrate and the cladding, it can be difficult, even impossible, to control the material distribution throughout the forming process.

The objective of the presented work is to evaluate the potential of hot upsetting in terms of characterization of hot forgeability of cladded work pieces according to the three levels defined above. So far, there has been little active research on the forgeability of bi-material cladded work pieces generated by arc welding. This paper presents experimental, analytical and numerical studies on hot upsetting tests to determine the hot forgeability of cladded work pieces.

Firstly, the article gives a brief state of the art concerning the forgeability of carbon steel and stainless steel, depositing stainless steel on mild steel and the forming of multi-material. Secondly, the experimental setup and results obtained in the upsetting test of cladded billets are presented. Then, two models of upsetting tests are introduced where the first is based on the slab method and the second on a finite element modeling. The last part is devoted to studying the simulation predictions and comparing them with the experimental results.

\section{State of the arts}

\subsection{Forgeability and related experimental test of mild steel and stainless steel}

One definition of forgeability is that it is the relative ability of a material to flow under compressive loading without cracking. Most carbon and low-alloy steels are usually considered to have good forgeability, except for resulfurized and rephosphorized grades as referred by Van Tyne (2005). Stainless steels, based on forging pressure and load requirements, are considered to be more difficult to forge than carbon or low-alloy steels, primarily because of the greater strength at elevated temperatures and limitations on the maximum temperature at which they can be forged without incurring microstructural damage as shown by Mochnal (2005). Forgeability or workability is evaluated in several ways through various types of tests reviewed by Dieter (2005). These tests are commonly applied to mono-material samples to characterize the flow stress of the material in relation to the temperature, the plastic strain and the plastic strain rate. Tensile tests or upsetting tests are also applied to assess the ductility limit. The principle of these tests consists in measuring the testing load as a function of the testing displacement, measuring the shape of the sample and analyzing the occurrence of cracks. These features are linked to the material properties thanks to models generally based on the assumption of homogeneity of the material. As this cannot be the case when considering a multi-material sample, the relation between the testing load and displacement and the local thermomechanical parameters needs more complex modeling like finite element model taking into account the behavior of both materials and the interface.

\subsection{Weld cladding of stainless steel on mild steel substrate}

The technique of weld cladding represents a method that can be used to impart different surface properties to a substrate that are not available from that base metal, or to conserve expensive or difficult-to-obtain materials by using only a relatively thin surface layer on a less expensive or abundant base material as reviewed by Davis (1993). Various processes like submerged arc welding (SAW), gas tungsten arc welding (GTAW), plasma arc welding (PAW), gas metal arc welding (GMAW), universal gas metal arc welding (UGMAW), electro slag welding (ESW), strip cladding, explosive welding, friction welding, etc. have been used for cladding operation with an aim to minimizing dilution without sacrificing the joint integrity. Govardhan et al. (2012) have carried out research on the characterization of austenitic stainless steel deposited by friction welding on low carbon steel substrates. Selection of the most appropriate welding process is largely dependent on factors such as the size of the clad area, access to the area to be cladded, alloy type and specified clad thickness, chemical composition limits, welding position and Non Destructive Testing acceptance standards. For example, Brown (2005) has studied the possible application of weld overlay cladding in the field of pumps to resolve corrosion problems.

The structure of the stainless steel deposited on carbon or lowalloy steel may vary from full martensitic to full austenitic to a mixture of the two with ferrite. This variation in structure depends on local compositional gradients and diffusion effects. Lippold and Kotecki (2005) have found that dissimilar metal welds between carbon steel and stainless steel can exhibit a number of crack mechanisms like solidification crack, clad disbanding, reheat or PWHT (Post Weld Heat Treatment) crack and creep failure in HAZ (Heat Affected Zone).

\subsection{The forgeability of multi-material}

In some applications the forged properties achieved from a single piece of monolithic bar stock cannot be tailored to satisfy all the design requirements that may exist at different locations in a part. To resolve this issue, bi-material forging, which has a substantial impact on the operating efficiency of the parts, is performed. Use of a bi-material preform could also minimize material cost while fulfilling the necessary design requirements.

Presently, little work has been carried out on the forging of bi-metal. The feasibility of the welded preform concept was previously used by Domblesky et al. (2006). They studied the hot forging behavior of different materials such as: copper, aluminum, steel and 304 stainless steel. Same and dissimilar metals preforms produced by friction welding, consisting of two cylindrical specimens in which one is placed on top of the other, are upset and side-pressed to assess workability and the resulting mechanical properties (see Fig. 3). As shown in Fig. 3, in bi-metal preforms, deformation occurs preferentially in the lower strength specimen during upsetting and tensile tests of side-pressed preforms. Fracture was found to be ductile and to occur away from the weld region. The intrinsic forgeability of all the materials involved is good (forgeability of Level 1). The welding bound is strong enough to resist deformation (forgeability of Level 2). But the flow stress differences in various materials could lead to a bad global forgeability, 


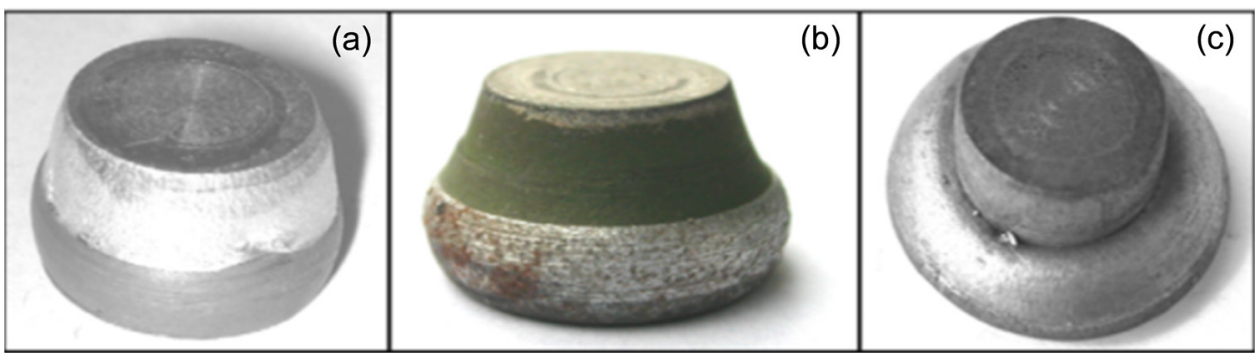

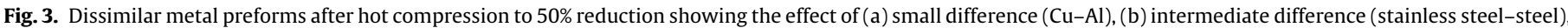
(c) large difference (steel-cu) in flow stress between the base metals (Domblesky et al., 2006)

namely an inability to control the material distribution (forgeability of Level 3).

The preforms studied above are assemblages of two dissimilar metals. Essa et al. (2012) have studied the cold upsetting of bi-metallic ring billets. In their study, preforms consisting of an outer ring of non-alloy steel C45E (EN 1.1191) surrounding a solid cylinder of non-alloy steel C15E (EN 1.1141) are compressed with flat platens of alloyed steel. As shown on Fig. 4, there is no mechanical, welded or metallurgical bond between the two materials. The objective is then to determine the scope for cold forging of bi-metal preforms with no pre-process interface bond. The study has shown that under certain conditions, bi-metallic rings may be upset while maintaining a good interfacial contact between the two components within a range of geometries. The increase of interface friction effect will increase the surface contact.

(a)
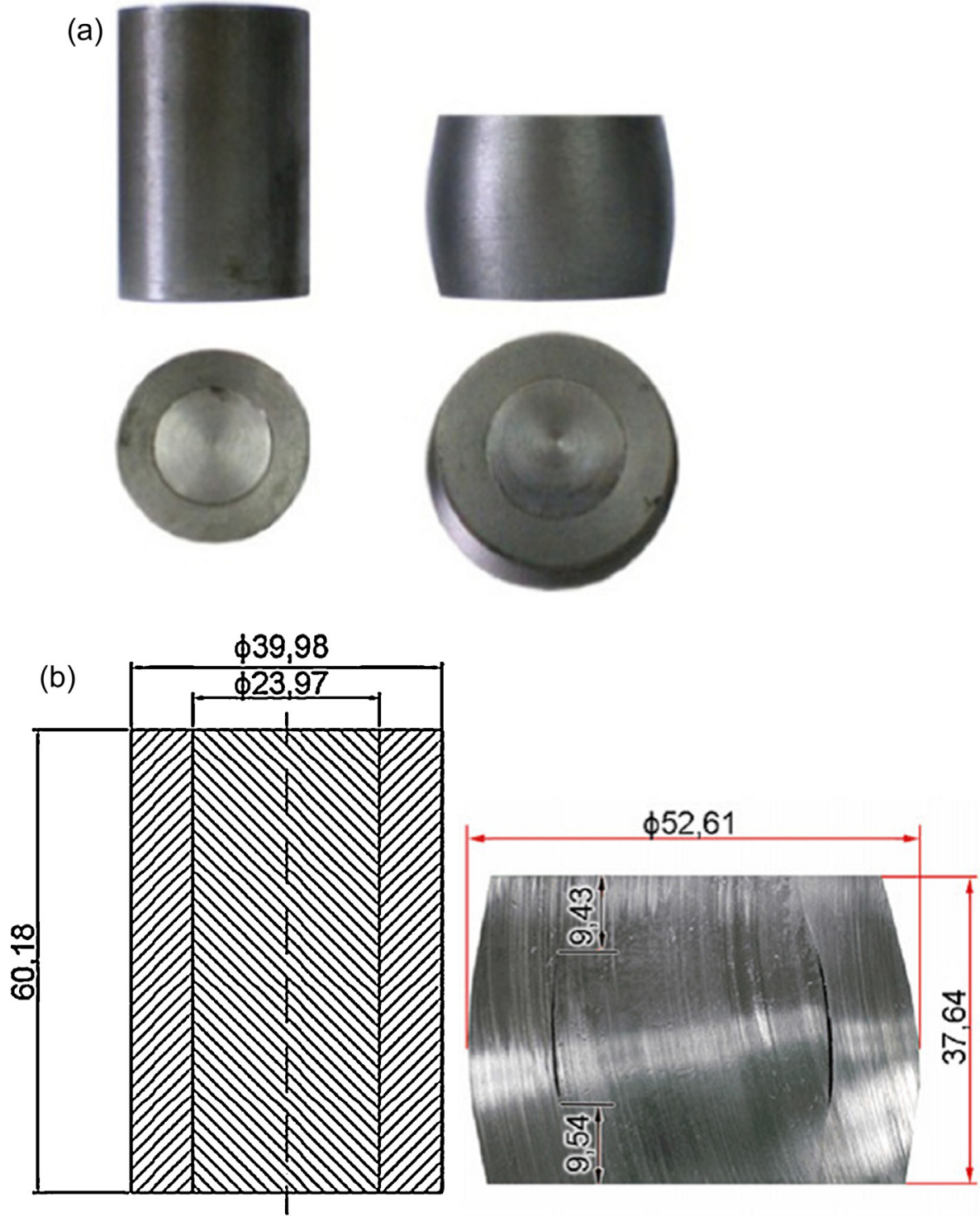

Fig. 4. Initial and compressed billet (a) initial and compressed bi-metal ring and (b) meridian cross section of bi-metal ring after compressed (Essa et al., 2012). 
Table 1

Welding parameters.

\begin{tabular}{|c|c|c|c|c|c|c|c|}
\hline Parameters & $\begin{array}{l}\text { Nozzle-to-bar } \\
\text { distance (mm) }\end{array}$ & $\begin{array}{l}\text { Wire feed speed } \\
(\mathrm{mm} / \mathrm{s})\end{array}$ & Voltage (V) & $\begin{array}{l}\text { Welding speed } \\
(\mathrm{mm} / \mathrm{s})\end{array}$ & $\begin{array}{l}\text { Protection gas } \\
\text { (\% in volume) }\end{array}$ & Generator & Welding machine \\
\hline Value & 16 & 4.2 & 22 & 5.3 & $\begin{array}{l}\text { Ar } 96 \%, \mathrm{CO}_{2} 3 \% \text {, } \\
\mathrm{H}_{2} 1 \%\end{array}$ & CY385MPR & $\begin{array}{l}\text { 6-Axes } \\
\text { polyarticular robot } \\
\text { (SCS) }\end{array}$ \\
\hline
\end{tabular}

Different from the models above, the specimen studied in this paper consists of a welded bond between the outer cladding and inner cylinder. Upsetting tests are performed to evaluate the deformation behavior of the interface and the forging load.

\section{Experimental}

\subsection{Experimental details}

In the upsetting test, a cylindrical work piece is upset between two flat dies to a pre-fixed ratio. The cladded specimens are obtained by cutting a weld cladded bar. A mild steel bar $(0.15 \%$ C, $0.45 \% \mathrm{Mn}, 0.2 \% \mathrm{Si}, 0.023 \% \mathrm{P}$ and $0.023 \% \mathrm{~S}$ ) with a diameter of $\emptyset 27 \mathrm{~mm}$ was cladded using a stainless steel $(0.02 \% \mathrm{C}, 1.8 \% \mathrm{Mn}$, $0.33 \% \mathrm{Si}, 0.023 \% \mathrm{P}, 0.013 \% \mathrm{~S}, 17.5 \% \mathrm{Cr}, 2.55 \% \mathrm{Mo}$ and $12.2 \% \mathrm{Ni}$ ) wire of diameter $1.0 \mathrm{~mm}$ by GMAW process on rotating welding platforms. The clad bar is then cut into $45 \mathrm{~mm}$-long specimens. The main parameters of the GMAW cladding process are shown in Table 1.

The macrograph of the meridian cross section of a cladded billet is shown in Fig. 5. The cladding/substrate interface exhibits a wavy morphology. The mean cladding thickness is about $3 \mathrm{~mm}$. For a $45 \mathrm{~mm}$ long billet, there are about 10 beads. The cladding is composed of juxtaposed bead rings (not a coil). The beginning of the bead overlaps the end of same bead, which is responsible for the build-up of the clad layer that could be observed on the left in Fig. 5. The overall dilution rate between the filler material and the substrate is about $10 \%$. This relatively low dilution value for GMAW cladding is achieved thanks to the overlapping.

The setup for the experimental upsetting test is shown in Fig. 6. A hydraulic press “Loire ACB” having a maximum load of $6000 \mathrm{kN}$ was used. The specimens were heated for $15 \mathrm{~min}$ at a constant temperature in an electric furnace (see Fig. 6(b) and Table 2) under normal atmosphere, while the dies were not preheated.

Two types of flat dies were used: striated and smooth dies. Upsetting tests were performed with smooth dies (lubricated and dry) and striated dies. The lubricant consisted of a mixture of oil and graphite (shell fenellor oil fluid F3802 G) which was deposited on the smooth die with a brush before each test. Regarding the striated

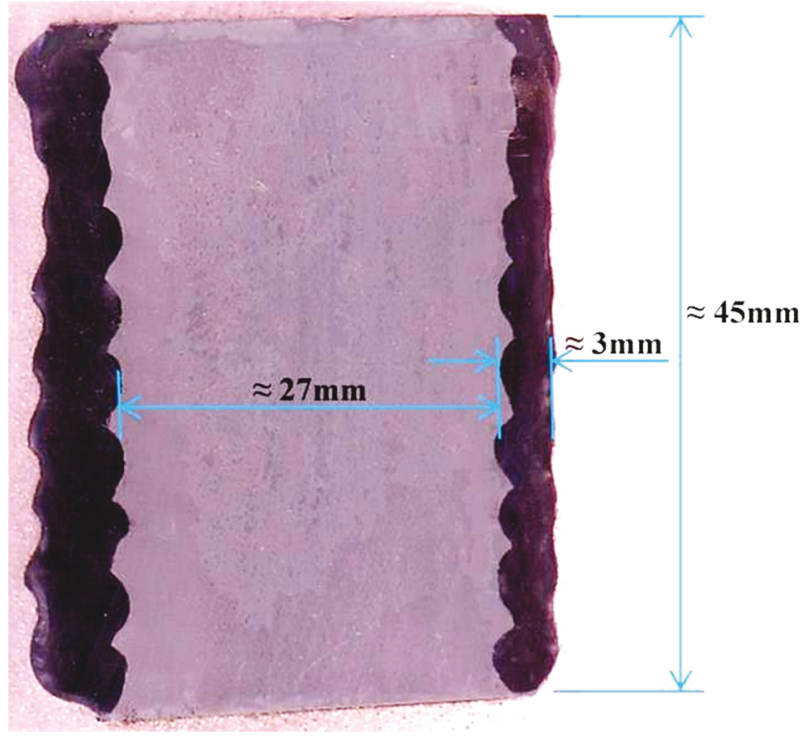

Fig. 5. Macrograph of the meridian cross section of the clad billet.

Table 2

Variables considered in performed upsetting tests.

\begin{tabular}{llll}
\hline Tool/temperature $\left({ }^{\circ} \mathrm{C}\right)$ & Clad billet & & \\
\cline { 2 - 4 } & 750 & 900 & 1050 \\
\hline Striated die & Yes & Yes & Yes \\
Dry smooth die & Yes & - & Yes \\
Lubricated smooth die & Yes & - & Yes \\
\hline
\end{tabular}

dies, the striation consisted of many concentric circular grooves on the surface of the die. The distance between two successive grooves was about $1 \mathrm{~mm}$ with a depth of $1 \mathrm{~mm}$. The specimens were taken out of the furnace and upset immediately. The upset velocity was constant about $30 \mathrm{~mm} / \mathrm{s}$. Specimens were upset to various upsetting ratios with the help of stop blocks placed between the die holders. Depending on the appearance of the crack, the upset ratio
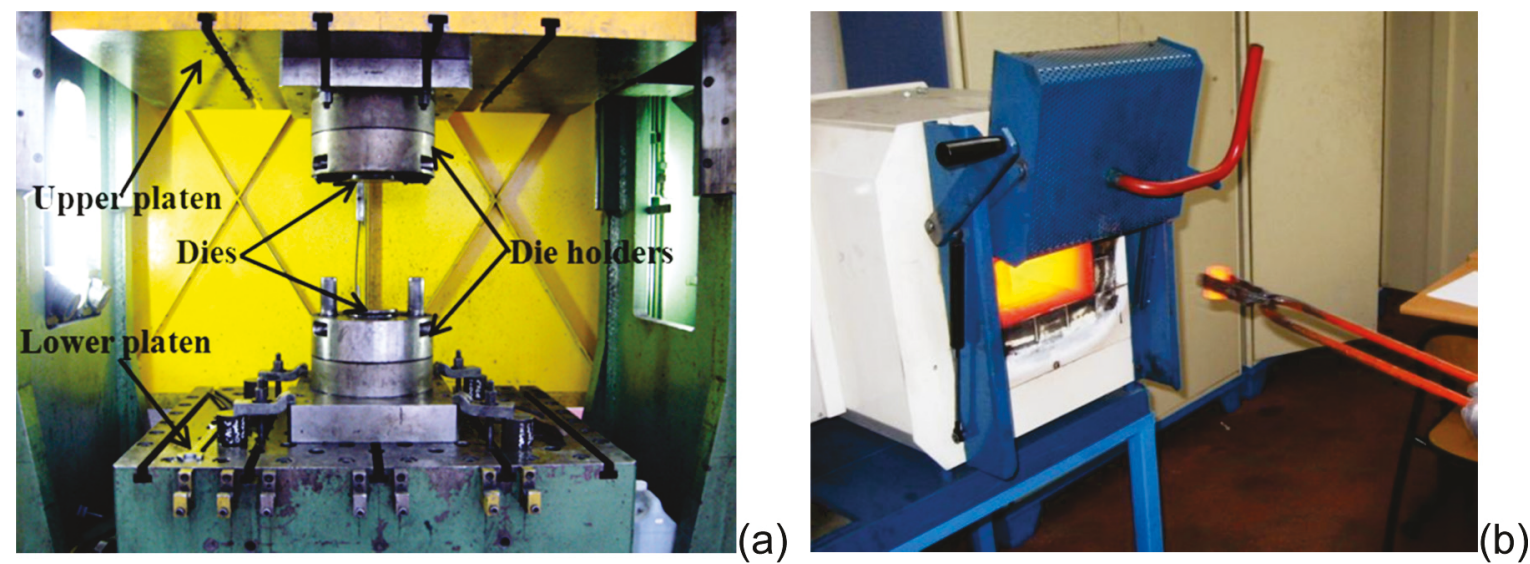

Fig. 6. Setup for experimental upsetting test, (a) upsetting setup and (b) furnace. 
Table 3

Cracks occurrence in tests performed using striated die.

\begin{tabular}{|c|c|c|c|c|c|c|}
\hline Temperature $\left({ }^{\circ} \mathrm{C}\right) /$ crack occurrence/\% upsetting & $50 \%$ & $60 \%$ & $63 \%$ & $65 \%$ & $67 \%$ & $70 \%$ \\
\hline 750 & No & No & - & Longitudinal & Longitudinal & - \\
\hline 900 & - & No & No & Longitudinal & Longitudinal & Longitudinal \\
\hline 1050 & - & No & - & - & - & Circumferential \& longitudinal \\
\hline
\end{tabular}

Table 4

Crack occurrence in tests performed using smooth die.

\begin{tabular}{|c|c|c|c|c|c|}
\hline Die & Temperature $\left({ }^{\circ} \mathrm{C}\right) / \%$ upsetting & $62 \%$ & $63 \%$ & $73 \%$ & $74 \%$ \\
\hline \multirow[t]{2}{*}{ Lubricated smooth die } & 750 & No & - & - & Longitudinal \\
\hline & 1050 & - & No & - & No \\
\hline \multirow[t]{2}{*}{ Smooth die } & 750 & Longitudinal & - & Longitudinal & - \\
\hline & 1050 & - & No & - & Longitudinal \\
\hline
\end{tabular}

of the next trial was increased or decreased. The upsetting ratio, $\delta$, is defined as the percentage reduction in length of the billet (see Eq. (1))

$\delta=1-\frac{h}{h_{0}}$

where $h$ and $h_{0}$ are respectively the instantaneous and the initial length of the billet.

Temperature and friction at the die/work piece interface are the two variables considered in the upsetting tests (see Table 2). Tests performed with a striated die are considered to have a very high friction coefficient at the die/work piece interface, approximating sticking condition. A dry smooth die represents medium friction coefficient, while a lubricated smooth die represents the lowest friction coefficient achievable experimentally. Three temperatures were chosen: $750^{\circ} \mathrm{C}, 900^{\circ} \mathrm{C}$ and $1050^{\circ} \mathrm{C}$. $700^{\circ} \mathrm{C}$ is in the temperature range of warm forging. $1050^{\circ} \mathrm{C}$ is in the temperature range of hot forging of both materials. $900^{\circ} \mathrm{C}$ is in the temperature range of hot forging of mild steel but represents the lower limit temperature of hot forging for stainless steel (Mochnal, 2005).

\subsection{Experimental results}

The results presented in this section concern three parts: the ductility limit, the obtained material distribution and the forging load. The ductility limit is defined by the maximum upsetting ratio achieved without crack forming. The material distribution was observed thanks to meridian cross section of the upset billet and corresponded to substrate and cladding morphology. The forging load was considered throughout the upsetting and was provided by the sensor of the hydraulic press.

For clad billets, two types of cracks were observed in the experimental tests: longitudinal and circumferential cracks (see Fig. 7). The (longitudinal and circumferential) cracks were observed to occur only in the clad layer and never propagated into the substrate. The circumferential cracks occurred in the thinner part of the cladding with a direction relative to the beads. Up to a $70 \%$ upset ratio, longitudinal cracks were observed to occur in all tests performed with a smooth die or a striated die, while circumferential cracks occurred only in tests performed using a striated die at $1050^{\circ} \mathrm{C}$.

The cracks are detected visually and by dye penetrant test performed after the specimens were completely cooled to room temperature after hot upsetting. The temperature, friction condition at die/work piece interface and upsetting ratio are main driving forces for crack occurrence as shown in Tables 3 and 4. The ductility increases with increasing temperature. In upsetting tests performed using the same friction conditions, cracks occurred more frequently at lower temperature and higher upsetting ratio. Furthermore the friction condition at the die/work piece interface mainly affects the crack type.

The longitudinal cracks are typical during the upsetting of mono-material. They correspond to ductile cracks when the material at the surface of the billet reaches its ductility limit. The circumferential cracks are specific to the upsetting of clad billets. Several potential explanations for the cracking phenomenon are
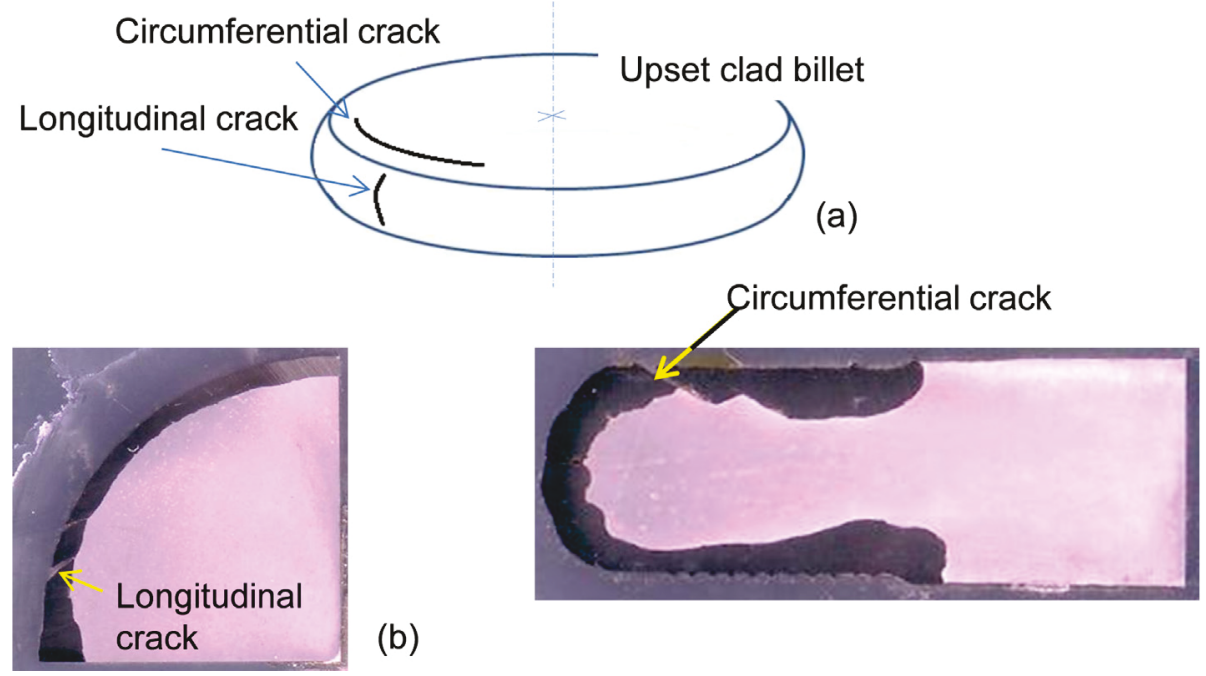

(c)

(b)

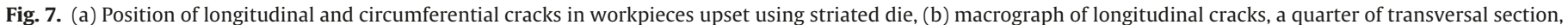
at $900^{\circ} \mathrm{C}$ and (c) circumferential crack, half of meridian cross section, at $1050^{\circ} \mathrm{C}$. 


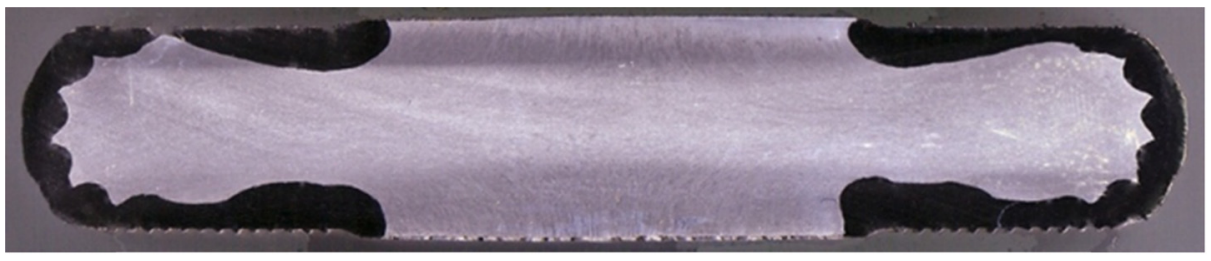

(a)

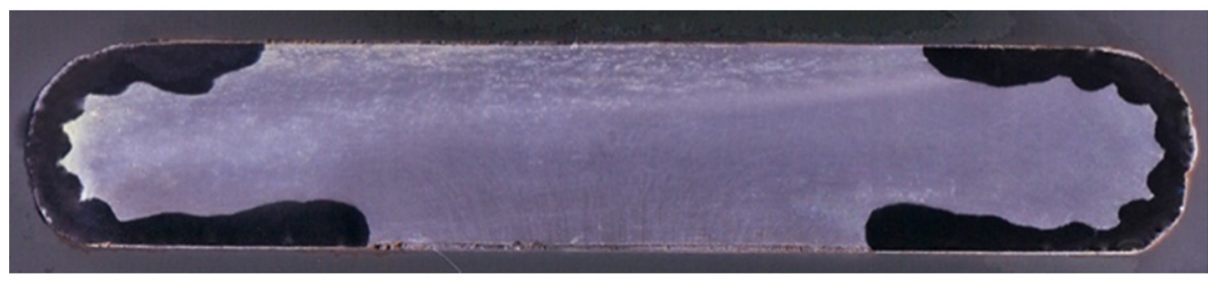

(b)

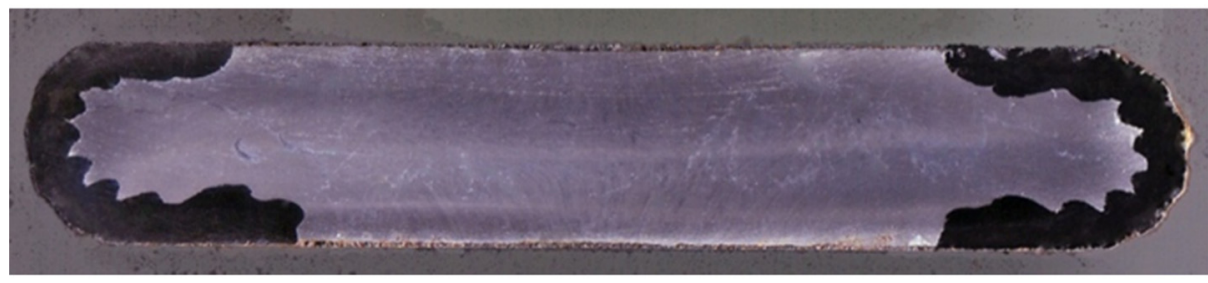

(c)

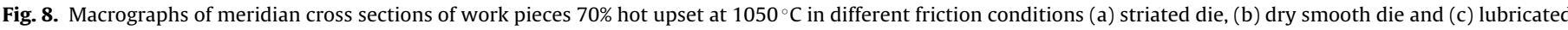
smooth die.

proposed. First, there might be a local effect of the die striation on crack as it occurred only in tests performed with striated dies. Secondly, the fact that the crack occurred at a certain location of the clad layer might be due to the effect of the bead orientation relative to the thermal mechanical loading. Indeed, the wavy morphology of the interface can generate stress concentration leading to the circumferential cracks. Finally, the area covered by the clad layer is more important in the case of striated dies than in the case of smooth dies. Thus, with a striated die, the clad layer is more stretched than in the other cases, which leads to early cracking.

The cracks never propagate into the substrate. One potential reason for this phenomenon may be that the ductility of mild steel is better than that of stainless steel. Another reason could be that due to material discontinuity the clad layer is more loaded than the substrate. Indeed, there might be a discontinuity of the stress through the substrate/cladding interface; the loading type (compression or tensile) can be different in different locations of the cladded billet, especially across the interface. The investigation of the stress across the interface and the effect of weld bead orientation are among the main objectives of the finite element simulation study.

The material distribution of the cladded billet after being hot forged is observed visually in the macrographs of meridian cross sections. The work piece is cut, polished and chemically etched for a few seconds by Nital $2 \%$ which can etch C15 but not SS316L, allowing to distinguish the interface between the two materials. The macrographs of the meridian cross section of work pieces upset in different conditions are shown in Fig. 8. The material distribution is the result of a combination of several factors. The dwell time (about $5 \mathrm{~s}$ ) between placing the billet on the lower die and the beginning of the forging, friction condition at the die/work piece interface, the wavy morphology of substrate/cladding interface and the ductility of materials constituting the substrate and the clad layer are main driving forces of material distribution during the hot upsetting test.

According to Fig. 8, the substrate after upset is composed of a central trunk surrounded by a ring-like part (see Fig. 9). The area of the upper/lower surface covered by clad layer depends on the diameter of the central trunk. The diameter of the central trunk mainly depends on the friction condition at the die/work piece interface.
For specimens upset with a striated die, the diameter of the central trunk is smaller and the clad layer is more elongated than for those upset with a dry or a lubricated smooth die, because the material of the substrate can slide more easily on them. The material distribution is less influenced by temperature.

The material distribution is asymmetric between the upper and lower surface of the upset billet. This phenomenon is probably caused by the dwell time before upsetting during which the billet is chilled by the lower die. Therefore, the material in the lower part of the billet is colder, causing greater flow stress. This phenomenon emphasizes the important effect of heat exchange on the material distribution of hot-upset clad billets. In tests performed with a striated die, the material is prevented from sliding on the die surface. The upper and lower surfaces of the substrate remain nearly unchanged during the test, hence the symmetric distribution.

The forging load and displacement were directly provided by the sensors in the hydraulic press. The forging load is calculated from the pressure in the main cylinder of the machine. Fig. 10 shows the curves of the forging load as a function of the upsetting ratio of hot upsetting tests performed in different conditions.

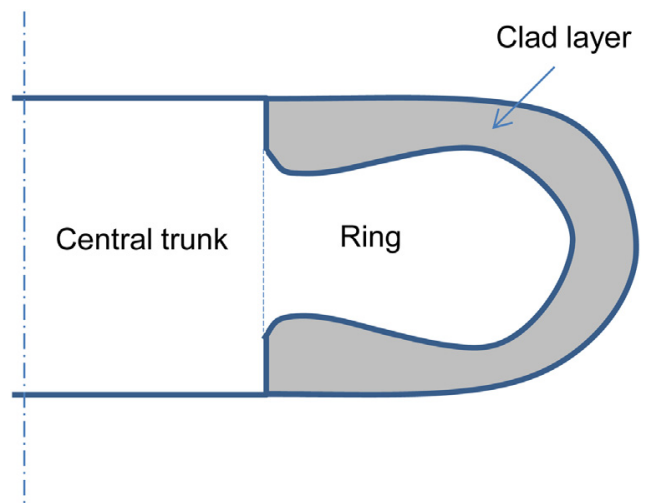

Fig. 9. Schematic of material distribution in an upset clad billet. 
Table 5

Parameters of the hydraulic press.

\begin{tabular}{|c|c|c|c|c|c|}
\hline Parameters & Initial height of upper die (mm) & Final height of upper die (mm) & Direction & Speed $(\mathrm{mm} / \mathrm{s})$ & Initial waiting time $(\mathrm{s})$ \\
\hline Value & 46 & 13.5 & $-Z$ & 30 & 5 \\
\hline
\end{tabular}

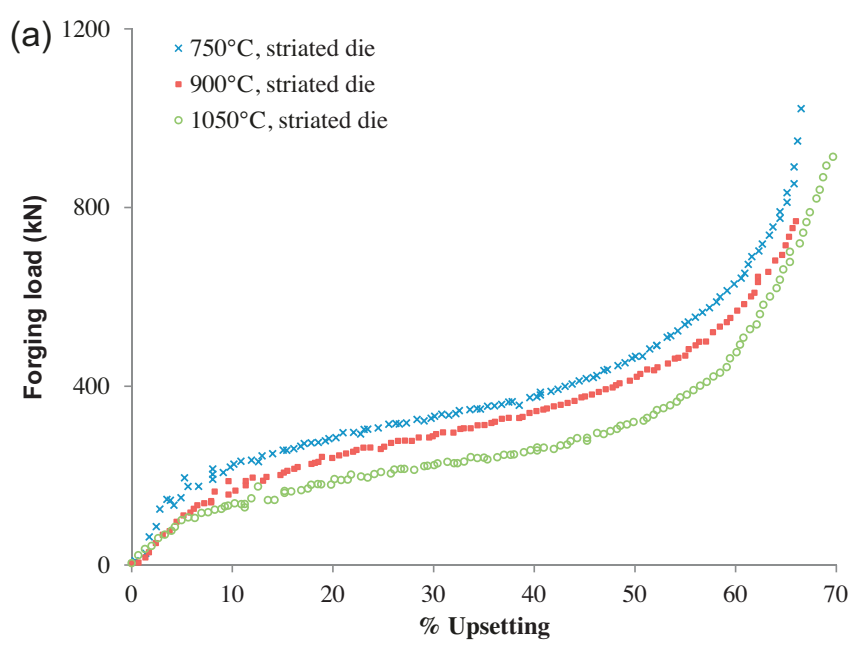
(b) $12007 \cdot 1050^{\circ} \mathrm{C}$, lubricated
- $1050^{\circ} \mathrm{C}$, non lubricated
$\times 1050^{\circ} \mathrm{C}$, striated

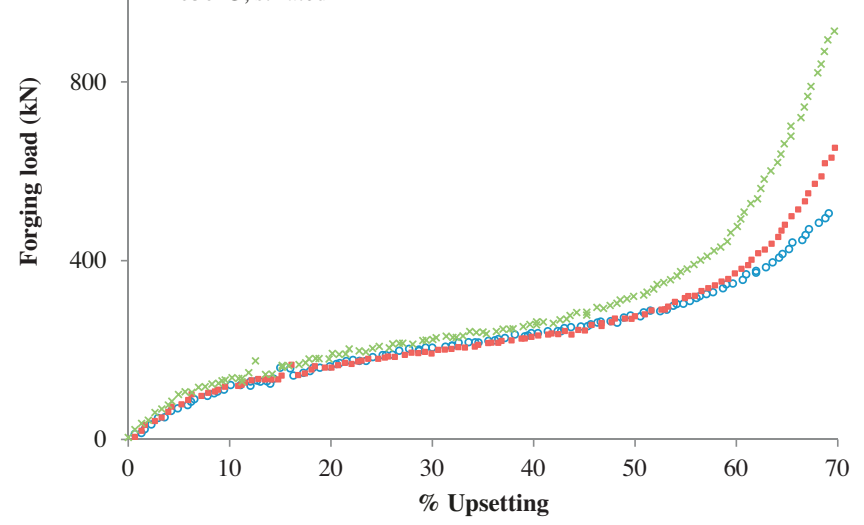

Fig. 10. Hot upsetting tests of clad billets performed in different conditions (a) at different temperatures and (b) in different friction conditions.
The forging load increases with the upsetting ratio, temperature and friction at the die/work piece interface. The temperature affects the whole curve, while the friction is more sensitive to the latter part of the upsetting test. These effects are the same as hot upsetting of both mono-material billet as shown by Lin (1995) and clad billet.

\section{Modeling and simulations}

The upsetting test was also studied analytically and numerically and this part is devoted to the modeling and simulation of the bimaterial upsetting test. It aims to construct a model to explain the crack phenomenon in the cladded billet, to estimate material distribution and forging load, and to study the effect of the process parameters.

\subsection{Modeling}

In the analytical analysis, the slab method was applied. The parameters of the model are shown in Fig. 11. Values of the parameters are given in Table 5 .

The cylindrical symmetry of the problem requires a velocity field in the bar in the following form:

$\vec{v}(r, z)=v_{r}(r, z) \overrightarrow{e_{r}}+v_{z}(r, z) \overrightarrow{e_{z}}$

The clad billet is assumed to remain cylindrically symmetric and its bulging is neglected. The temperature of the billet is assumed to be constant and uniform during the upsetting. Thermal exchange with the dies and energy dissipation are neglected. According to these assumptions, and considering the principle of mass conservation, the velocity field is obtained as below:
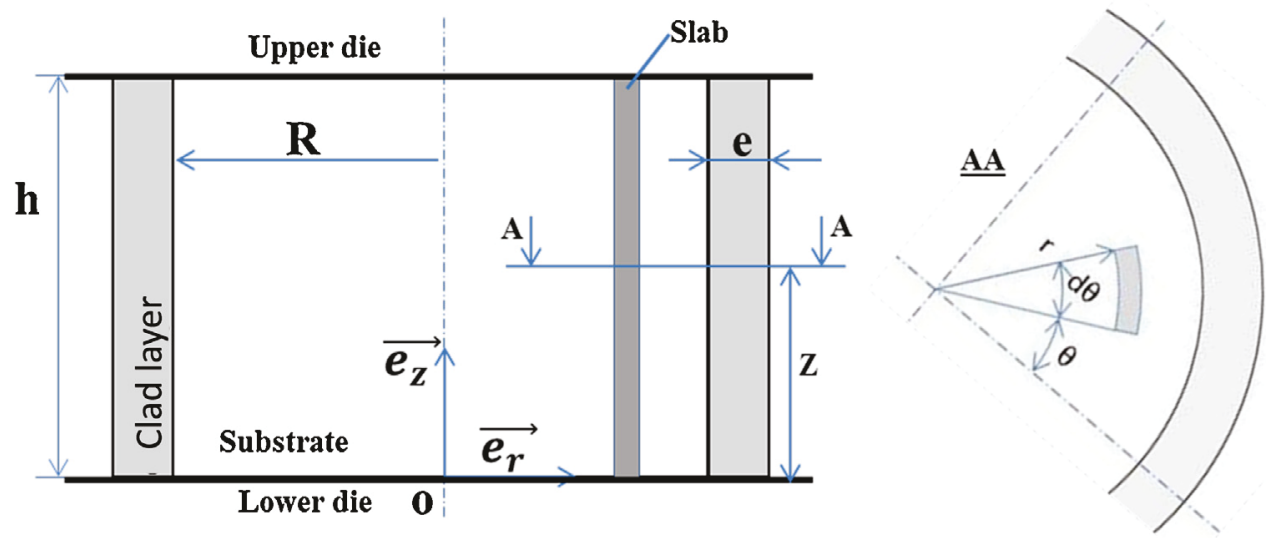

Fig. 11. Slab method applied to a clad. 
The plastic strain $\varepsilon^{p}$ and the plastic strain rate $\dot{\varepsilon}^{p}$ are uniform in the clad billet and given by Eqs. (4) and (5).

$\varepsilon^{p}=\left(\begin{array}{ccc}-\frac{1}{2} & 0 & 0 \\ 0 & -\frac{1}{2} & 0 \\ 0 & 0 & 1\end{array}\right) \ln \left(\frac{h}{h_{0}}\right)$

$\dot{\varepsilon}^{p}=\left(\begin{array}{ccc}-\frac{1}{2} & 0 & 0 \\ 0 & -\frac{1}{2} & 0 \\ 0 & 0 & 1\end{array}\right)\left(\begin{array}{l}\dot{h} \\ \bar{h}\end{array}\right)$

with $h$ and $h_{0}$ the instantaneous and initial length of the billet respectively and $\dot{h}$ the upsetting velocity.

Von Mises plasticity criterion is adopted. In that case, the deviatory stress is parallel to strain rate and the equivalent stress is equal to the flow stress of the material. The expression of the stress tensor $\sigma$ and the deviatoric stress tensor $s$ are given by Eqs. (6) and (7) in the cylindrical coordinate reference (see Fig. 11):

$\sigma=\left(\begin{array}{ccc}\sigma_{r r} & \tau_{r \theta} & \tau_{r z} \\ \tau_{r \theta} & \sigma_{\theta \theta} & \tau_{\theta z} \\ \tau_{r z} & \tau_{\theta z} & \sigma_{z z}\end{array}\right)$

$S=\left(\begin{array}{ccc}\frac{2}{3} \sigma_{r r}-\frac{1}{3}\left(\sigma_{\theta \theta}+\sigma_{z z}\right) & \tau_{r \theta} & \tau_{r z} \\ \tau_{r \theta} & \frac{2}{3} \sigma_{\theta \theta}-\frac{1}{3}\left(\sigma_{r r}+\sigma_{z z}\right) & \tau_{\theta z} \\ \tau_{r z} & \tau_{\theta z} & \frac{2}{3} \sigma_{z z}-\frac{1}{3}\left(\sigma_{r r}+\sigma_{\theta \theta}\right)\end{array}\right)$

The plasticity criterion, assuming that $s$ is proportional to the plastic strain rate tensor $\dot{\varepsilon}^{p}$, gives:

$\tau_{r \theta}=\tau_{r z}=\tau_{\theta z}=0$

and

$\sigma_{r r}=\sigma_{\theta \theta}$

The stress tensor can be simplified as Eq. (9):

$\sigma=\left(\begin{array}{ccc}\sigma_{r r} & 0 & 0 \\ 0 & \sigma_{r r} & 0 \\ 0 & 0 & \sigma_{z z}\end{array}\right)$

According to the plasticity criterion, the equivalent stress should be equal to the flow stress of the material $\sigma_{0}$. Thus, the stress tensor becomes:

$\sigma=\left(\begin{array}{ccc}\sigma_{r r} & 0 & 0 \\ 0 & \sigma_{r r} & 0 \\ 0 & 0 & \sigma_{r r}-\sigma_{0}\end{array}\right)$

where $\sigma_{0}$ is the flow stress of the material and $\sigma_{r r}$ is the normal stress in the direction $\overrightarrow{e_{r}}$. This relation is obtained by considering that the free lateral surface of the billet is free $\left(\sigma_{r r}=0\right)$ and the normal stress $\sigma_{z z}$ in the direction $\vec{e}_{z}$ is negative.

The fundamental principle of applied statics is applied to the slab bounded by:

$r \in[r ; \quad r+d r]$,

$\theta \in\left[\theta-\frac{d \theta}{2} ; \quad \theta+\frac{d \theta}{2}\right]$, $z \in[0, h]$

Considering the equilibrium in the direction $\overrightarrow{e_{r}}$, one can get:

$$
\begin{aligned}
& \left(\sigma_{r r}+d \sigma_{r r}\right)(r+d r) \cdot h \cdot d \theta-\sigma_{r r} \cdot r \cdot h \cdot d \theta-2 \sigma_{r r} h \cdot d r \cdot \sin \frac{d \theta}{2} \\
& \quad-2 \tau \cdot r \cdot d r \cdot d \theta=0
\end{aligned}
$$

where $\tau$ is the tangential stress at the tool/workpiece interface corresponding to friction. $\tau$ is negative and opposes the motion of material on the die. Developing the relationship of order 2 one can get:

$d \sigma_{r r}=-2 \frac{\tau}{h} d r$

Coulomb friction is assumed. In this case, the frictional shear stress is related to the normal pressure of contact by the following relation:

$\tau=-\mu \sigma_{n}$

with $\mu$ the friction factor and $\sigma_{n}$ the normal pressure on the diematerial contact.

In the slab method, the stress field is assumed to be uniform throughout the slab. The stress $\sigma_{z z}$ is the opposite of the contact pressure. One can get the following relation for the components of the stress $\sigma_{z z}$ which is applicable to both substrate and cladding:

$\frac{d \sigma_{z z}}{\sigma_{z z}}=-\frac{2 \mu}{h} d r$

The solution of Eq. (18) is given by Eqs. (19) and (20):

$r \in[0, R] \quad \sigma_{z z}=\lambda_{s} \cdot \exp \left(-\frac{2 \mu_{s}}{h} r\right)$

$r \in[R, R+e] \sigma_{z z}=\lambda_{s} \cdot \exp \left(-\frac{2 \mu_{r}}{h} r\right)$

where $e$ is the clad layer thickness and $R$ the radius of the substrate cylinder. In Eqs. (19) and (20), $\mu_{s}$ and $\mu_{r}$ are the tool/substrate and tool/clad layer friction coefficient respectively. $\lambda_{s}$ and $\lambda_{r}$ are two integration constants to calculate.

The boundary conditions at the external surface and substrate/clad layer interface are given by Eqs. (21) and (22):

$\sigma_{r r}(R+e)=0$

$\left\|\sigma_{r r}\right\|_{r=R}=0$

where $\left\|\sigma_{r r}\right\|_{r=R}$ is the discontinuity function of $\sigma_{r r}$ through the substrate/clad layer interface.

Considering Eq. (19) to Eq. (22), one gets:

$\lambda_{r}=-\sigma_{0 r} \exp \left(\frac{2 \mu_{r}(R+e)}{h}\right)$

$\lambda_{s}=\left(\sigma_{0 r}\left(1-\exp \left(\frac{2 \mu_{r} e}{h}\right)\right)-\sigma_{0 s}\right) \exp \left(\frac{2 \mu_{s} R}{h}\right)$

where $\sigma_{0 r}$ and $\sigma_{0 s}$ are respectively the flow stress in the clad layer and in the substrate.

The forging load, $F$, can be calculated as the integral of the contact pressure over the billet/die contact area:

$$
\begin{aligned}
F= & 2 \pi \int_{0}^{R+\theta}-\sigma_{z z} r d r=2 \pi \int_{0}^{R}-\lambda_{s} \cdot \exp \left(-\frac{2 \mu_{s}}{h} r\right) r d r \\
& +2 \pi \int_{R}^{R+\theta}-\lambda_{r} \cdot \exp \left(-\frac{2 \mu_{r}}{h} r\right) r d r
\end{aligned}
$$



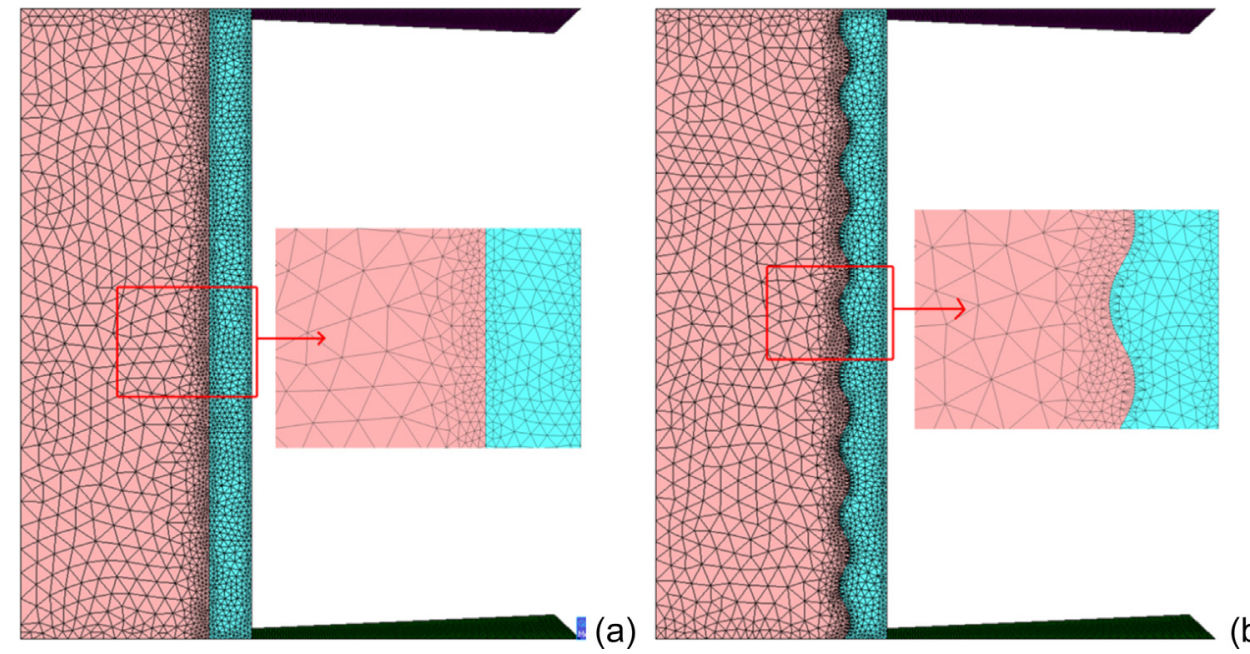

Fig. 12. Finite element modeling (a) with cylindrical interface and (b) with wavy interface billet.

Assuming that the friction coefficients $\mu_{s}$ and $\mu_{r}$ are equal to $\mu$, the forging load is given by Eq. (26):

$$
\begin{aligned}
F= & \frac{\pi h}{2 \mu^{2}}\left\{h \lambda_{s}+\exp \left(-2 \mu \frac{R}{h}\right)\left(\lambda_{r}+\lambda_{s}\right)(h+2 \mu R)\right. \\
& \left.-\exp \left(-2 \mu \frac{R+e}{h}\right) \lambda_{r}(h+2 \mu(R+e))\right\}
\end{aligned}
$$

$R$ and $e$ are functions of the initial geometry $\left(h_{0}, e_{0}, R_{0}\right)$ of the billet and the upsetting length, $h$. According to the principle of mass conservation:

$R=R_{0} \sqrt{\frac{h_{0}}{h}}$

$e=e_{0} \sqrt{\frac{h_{0}}{h}}$

Due to the fact that the temperature, strain and strain rate are assumed to be uniform over the billet, the solution of the differential Eq. (18) is independent of the constitutive law of the two materials. The integration constants defined by relations (23) and (24) can be calculated from the expression of flow stress defined by a simplified Hansel-Spittel law that is well suited to represent the hot forming behavior of metals:

$\sigma_{0}=A \cdot \exp \left(m_{1} T\right) \cdot \varepsilon^{m_{2}} \cdot \dot{\varepsilon}^{m_{3}} \cdot \exp \left(\frac{m_{4}}{\varepsilon}\right)$

where $\varepsilon$ and $\dot{\varepsilon}$ are the equivalent plastic strain and equivalent plastic strain rate respectively.

The Spittel law with associated coefficients is only valid for a given range of temperatures, strain and strain rate data for each material.

The forging load, calculated by the slab method, depends only on:

- The initial geometry of the clad billet $\left(h_{0}, e_{0}, R_{0}\right)$.

- The friction factor between the substrate/clad layer and die.

- The flow stress of the two materials.

\subsection{Finite element simulations}

The simulation analysis was carried out using Forge2011@. Considering the symmetry of the problem, a 2-D axisymmetric hot forging module was adopted.
The finite element simulation model is shown in Fig. 12. Considering the effect of the substrate/cladding interface, special attention was paid to the interface geometry, the re-mesh of the interface zone in the simulation model and the continuity condition through the interface.

Two types of substrate/cladding interface are adopted and compared in the study, a cylindrical one and a sinusoid one. The latter is implemented in order to estimate the effect of the wavy morphology of the substrate/clad layer interface. The geometrical parameters of the sinusoid interface (see Fig. 13) are calculated from the macrograph of Fig. 5.

Since the clad layer is obtained by welding, the velocity and temperature fields are assumed to be continuous through the interface, imposing the following boundary conditions:

$\|\vec{v}\|=\overrightarrow{0}$

$\|T\|=0$

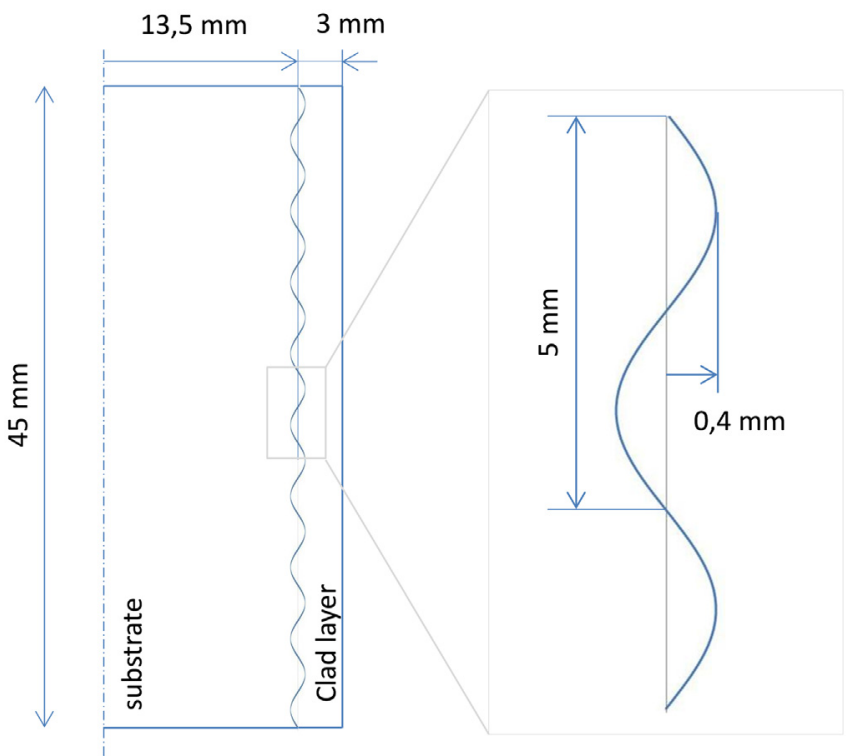

Fig. 13. Geometrical parameters of the wavy substrate/cladding interface in simulation. 


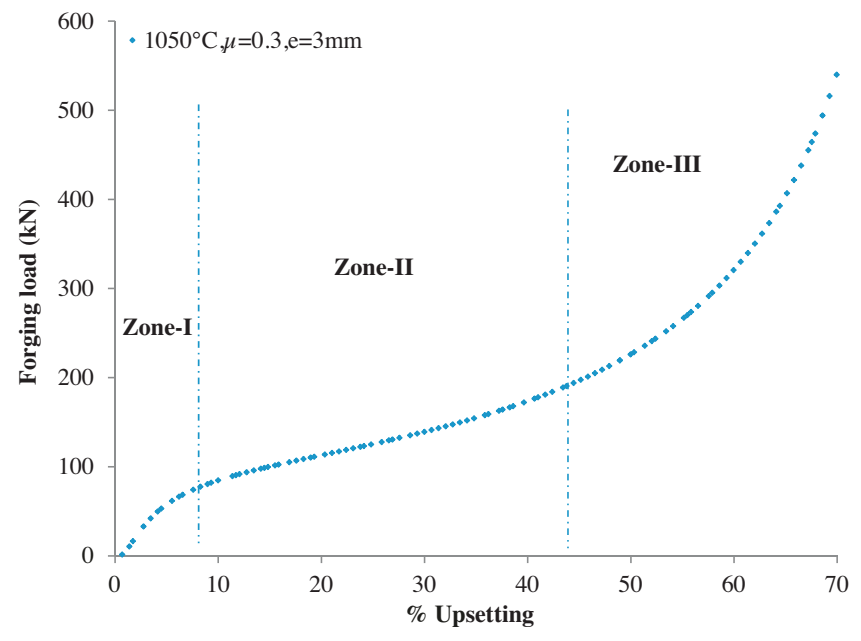

Fig. 14. Evolution of forging load in $70 \%$ upsetting test at $1050{ }^{\circ} \mathrm{C}$ based on slab method formulation.

where $\|\vec{v}\|$ and $\|T\|$ are respectively the discontinuity vector of the velocity and the discontinuity of the temperature through the substrate clad layer interface.

In this study, the substrate and the clad layer are two separate meshed objects. In order to approach the boundary conditions of Eqs. (30) and (31), a bilateral sticking condition is applied at the substrate/clad layer interface. A high heat exchange coefficient $\left(2 \times 10^{4} \mathrm{~W} \mathrm{~m}^{-2} \mathrm{~K}^{-1}\right)$ is applied in order to reduce the temperature discontinuity at the interface regardless of the heat flux. The mesh size of the clad layer is smaller than that of the substrate. Zones close to the interface have been re-meshed (see Fig. 12) to improve the continuity of the substrate/clad layer interface.

At the die/billet interface, heat exchange is driven by a constant coefficient while friction is modeled by a Coulomb law. The dies are considered to be rigid. The press is hydraulic as shown in Fig. 6. The forging operation is composed of a dwell time, during which the work piece is placed on the lower die, followed by subsequent upset operation.

Compared with an analytical analysis, the finite element simulation analysis considers the thermal conduction of materials. As for the slab method, the flow stress of the material is assumed to be governed by Hansel-Spittel. The thermal behavior of the material is defined by a conduction factor, a heat capacity and the density of the materials. At the die/billet interface, the repartition of the energy produced by the friction is governed by a classical law including thermal diffusivity of the materials. Finally, a constant convection factor is considered at the external surface of the clad billet to take into account the heat exchange with the environment.

\section{Results}

\subsection{Slab method}

The upsetting tests of clad billets are first studied analytically with the slab method. Fig. 14 shows the forging load during the upsetting test of a mild steel billet $(\varnothing 27 \mathrm{~mm} \times 45 \mathrm{~mm})$ cladded with stainless steel (thickness $e=3 \mathrm{~mm}$ ) at $1050^{\circ} \mathrm{C}$ using a friction coefficient of $\mu=0.3$ at the die/billet interface. The value of the coefficients in Hansel-Spittel law (taken from FORGE2011 ${ }^{\circledR}$ database) is given in Table 6. In this study, the effect of the dilution on the flow stress of the clad layer is not taken into account. The flow stress of the clad layer is assumed to be close to that of pure SS316L. In the developed slab method, the sticking condition
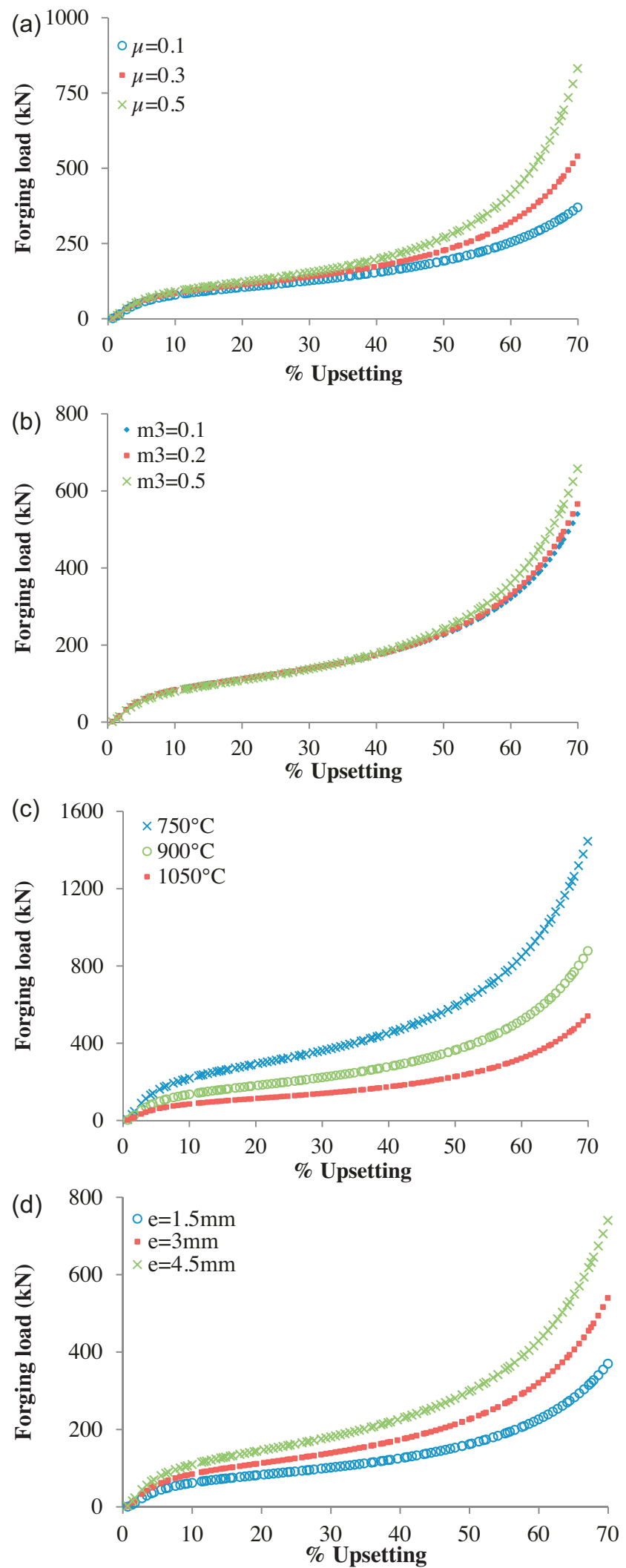

Fig. 15. Effect of different parameters on forging load.

could not be taken into account. Therefore, tests performed with a striated die are not included in this part.

The curve of forging load versus upsetting ratio in Fig. 14, similar to that of the experimental test, could be divided into three zones 
Table 6

Values of coefficients of the Hansel-Spittel law.

\begin{tabular}{|c|c|c|c|c|c|}
\hline \multirow[t]{2}{*}{ Material } & \multicolumn{5}{|c|}{ Coefficients of simplified Hansel-Spittel law } \\
\hline & $\mathrm{A}(\mathrm{MPa})$ & $m_{1}$ & $m_{2}$ & $m_{3}$ & $m_{4}$ \\
\hline Mild steel & 890.4543 & -0.00234 & -0.12626 & 0.13938 & -0.0477 \\
\hline Stainless steel & 8905.34 & -0.00383 & 0.01246 & 0.09912 & -0.02413 \\
\hline
\end{tabular}

in general. In Zone-I, the forging load increases sharply due to a hardening phenomenon. Zone-II is a transition between Zone-I and Zone-III. The inflexion of Zone-II is the smallest. In Zone-III, the forging load increases rapidly again with the increase of upsetting due to a combination of three main factors:

- Increase of the upper and lower surface of the billet.

- Increase of strain rate with the increase of upsetting ratio, the upsetting velocity being constant.

- An accumulation of tangential friction forces leading to an increase of hydrostatic pressure within the billet.

Variations in friction coefficient, temperature, cladding thickness and coefficients of Hansel-Spittel Law (especially $m_{3}$ ) have a great effect on the forging load (see Fig. 15). Variations in the friction coefficient and $m_{3}$ (viscosity coefficient) mainly affect Zone-III of the forging load/upsetting ratio curve (see Fig. 15(a) and (b)); the effect of $m_{3}$ is much weaker than that of friction. Generally, the value of $m_{3}$ for steels is less than 0.2. Temperature and cladding thickness impact the whole curve, their effect being greater on Zone-II and Zone-III (see Fig. 15(c) and (d)).

\subsection{Finite element model}

With the parameters given in Table 6 , simulations were conducted for the upsetting test of a clad billet at $1050^{\circ} \mathrm{C}$ with sticking friction at the die/billet interface.

\subsubsection{Material distribution}

The material distribution varies with variations in parameters of the upsetting test. Besides, the configuration of the substrate/cladding interface also affects material distribution, as shown in Fig. 16. The result of simulation with a wavy substrate/cladding interface is close to that of experimental testing. The deformation of the clad layer during the upsetting test is not uniform. The first two or three clad beads close to the upper and lower surface of the billet are stretched, the wavy aspect of the interface mitigating. Those in-between are compressed and bended, curvatures increasing. The edge areas of the upper and lower surfaces exhibit the thinnest clad layer. The clad layer is not symmetric between upper and lower surface. As mentioned in the part dedicated to the experimental results, this phenomenon is attributed to the initial dwell time (see Table 5) during which the billet is chilled by the lower die.
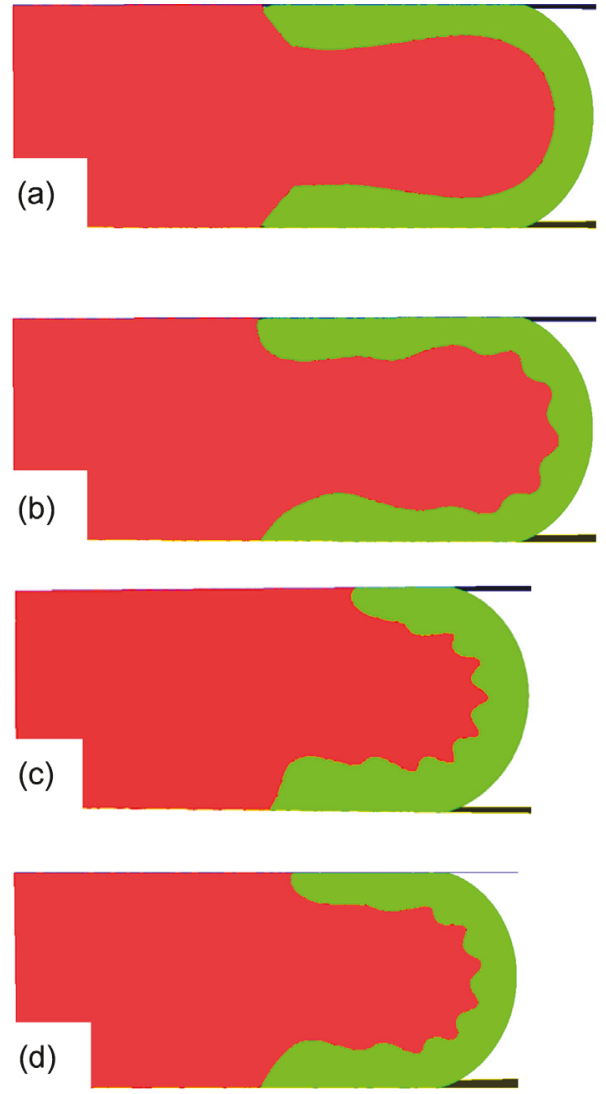
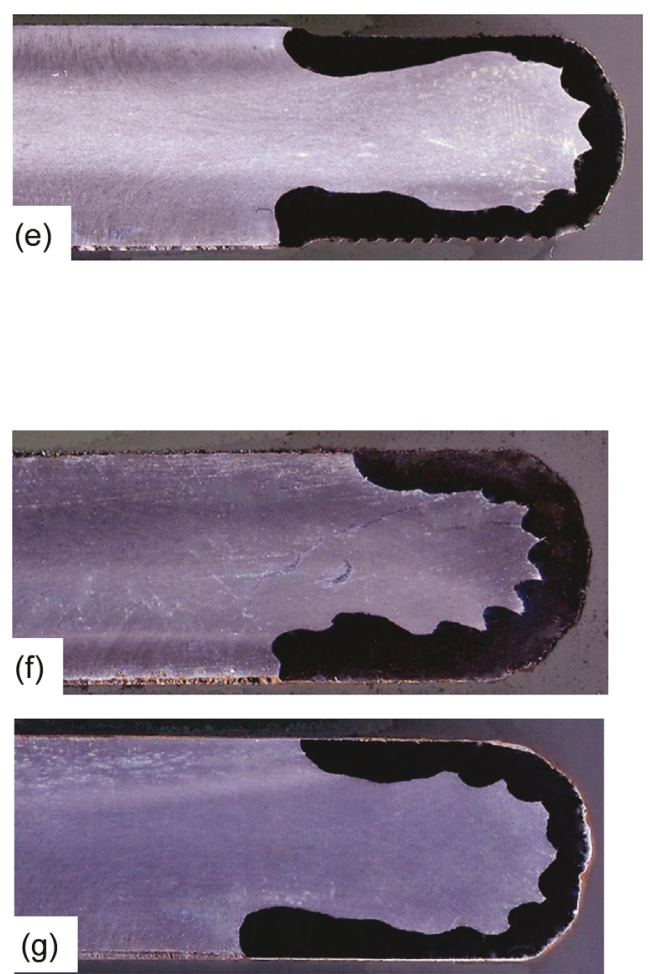

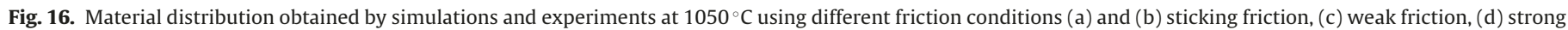
friction, (e) test performed using striated die, (f) test performed using lubricated smooth die and (g) test performed using dry smooth die. 
(a)

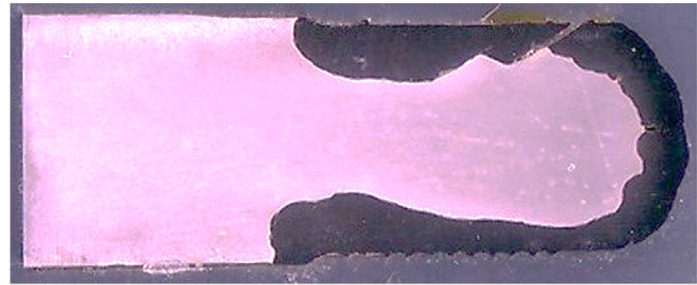

(b)

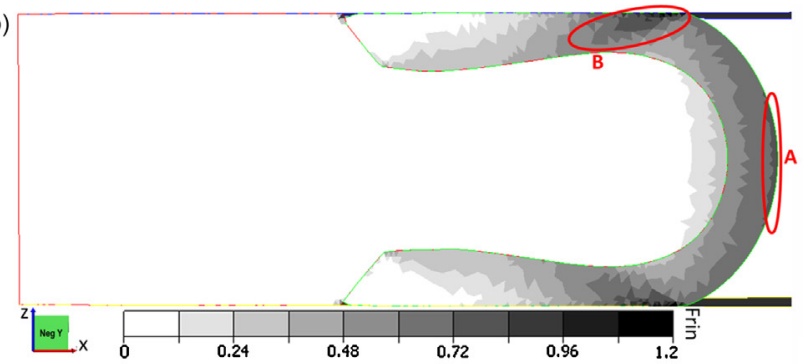

(c)

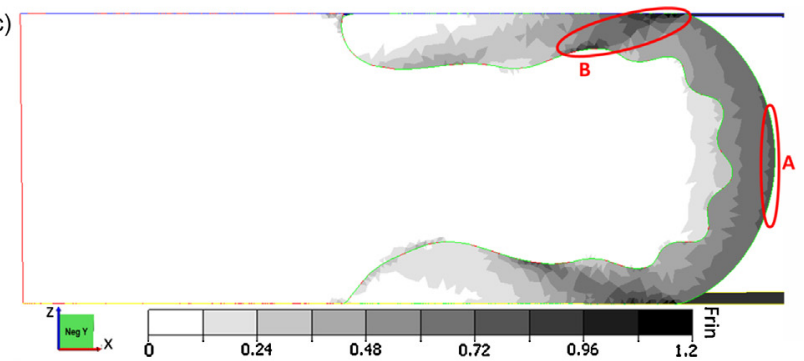

Fig. 17. Latham and Cockcroft criterion obtained for simulation of experiment performed using striated die at $1050^{\circ} \mathrm{C}$ (a) macrograph of half meridian cross section, (b) simulation with cylindrical substrate/cladding interface and (c) simulation with wavy substrate/cladding interface.

The configuration of substrate/cladding interface affects the material distribution (see Fig. 16(a) and (b)). However, the overall material distribution could be obtained even without considering the wavy morphology of the interface.

\subsubsection{Hot ductility criterion}

In Forge2011@, it is possible to estimate the probability of the damage of a workpiece by calculating the Latham and Cockcroft coefficient $L a$. This indicator was also used to predict the occurrence of crack. Its expression is given by Eq. (32).

$L a=\int_{0}^{\varepsilon} \frac{\sigma_{\max }}{\sigma_{\mathrm{eq}}} d \varepsilon$

where $\sigma_{\max }$ is the maximum principal tensile stress, otherwise it is equal to zero, and $\sigma_{\text {eq }}$ is the von Mises equivalent stress.

With this criterion, one can observe that the peripheral zone of the work piece is susceptible to rupture (see Zone A in Fig. 17(b) and(c)). This is classical for ductile cracks during upsetting test. In the case of striated dies, another zone (see Zone B in Fig. 17(b) and (c)) with high value of $L a$ appears. This zone corresponds to the circumferential crack observed in experiments performed with a striated die (see Table 3). Regardless of the cladding/substrate interface configuration, Zone B appears in all simulations with sticking friction.

It was experimentally observed that the cracks in Zone A and $\mathrm{B}$ occurred only in the cladding and never propagated into the substrate. This could be caused by the weak ductility of the cladding material at high temperature, but in Fig. 17(b) and (c) one can see that the La factor is negative or close to zero in the substrate. The

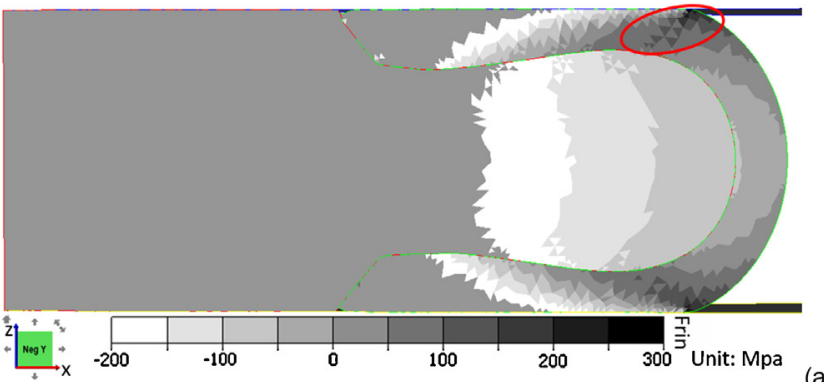

(a)

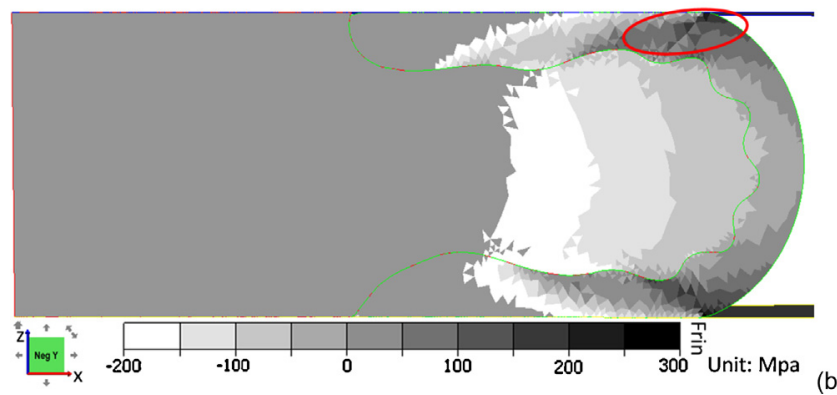

(b)

Fig. 18. Distribution of radial stress $\left(\sigma_{\mathrm{rr}}\right)$ obtained by simulation performed at $1050^{\circ} \mathrm{C}$ in sticking friction condition, (a) cylindrical interface and (b) wavy interface.

distribution of the radial stress of the simulation with a wavy substrate/cladding interface (70\% upset) is studied (see Fig. 18). In the big gray region, $\sigma_{r r}$ is less than $-200 \mathrm{MPa}, \sigma_{r r}$ being the leading stress for cracks occurring in Zone B. $\sigma_{r r}$ is positive in Zone B, but negative in the area of the substrate in the vicinity of Zone B. The only occurrence of crack in the clad layer is due in large part to the stress discontinuity through the interface as a result of a global bimaterial structure effect. Indeed, during the upsetting the clad layer is stretched and the inner substrate is compressed.

The evolution of the indicator La (see Fig. 19) helps to better understand the initiation and development of cracks occurring in Zone A and B. At $1050^{\circ} \mathrm{C}$, in the test performed with a striated die, there is a rapid increase in $L a$ in Zone B at the end of upsetting whereas this phenomenon does not exist in tests performed with a dry smooth die $(\mu=0.3)$ or a lubricated smooth die $(\mu=0.15)$. During upsetting performed using smooth dies, the value of $L a$ in zone $\mathrm{A}$ is always greater than that of Zone B.

According to the Latham and Cockcroft criterion, cracking occurs when La given by Eq. (32) is higher than a critical value depending on the temperature. The upsetting temperature has a slight effect on the value of $L a$ as shown in Fig. 20. According to Table 3, longitudinal cracks were observed on a billet upset at $900{ }^{\circ} \mathrm{C}$ using a striated die for an upset ratio of about $65 \%$. This value corresponds to a value of $L a$ of 0.55 in Zone A and 0.4 in zone B (see Fig. 20). At $1050^{\circ} \mathrm{C}$ using a striated die, longitudinal and circumferential cracks were experimentally observed for an upset ratio of $70 \%$. The corresponding simulations predicted the simultaneous occurrence of both types of crack for an upset ratio of about $68 \%$ with a critical $L a$ value of 0.6 . The finite element simulation, using a Latham and Cockcroft criterion, is able to predict the location of the cracks and, by inverse analysis, it is possible to estimate the critical value of $L a$ for the testing temperatures.

\subsubsection{Forging load/upsetting ratio}

Similar to that of the experimental test and the slab method, the forging load/upsetting ratio curve could be divided into three zones in general. Besides the reasons referred to above, another reason for the rapid increase in Zone-III is the cooling of the billet during upset which increases the flow stress of the materials. 

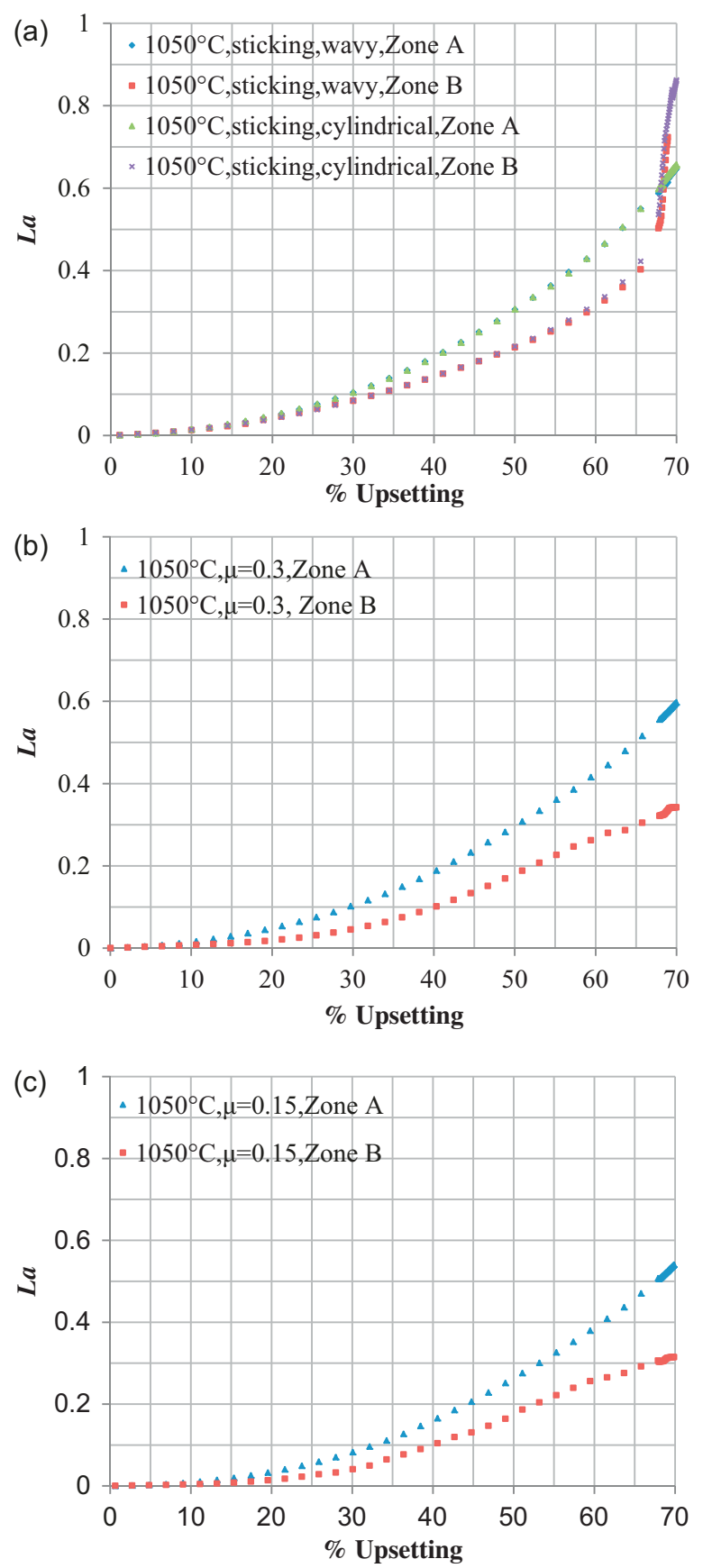

Fig. 19. Evolution of the indicator $L a$ (a) sticking friction and different substrate/cladding interface, (b) strong friction and wavy substrate/cladding interface and (c) weak friction and wavy substrate/caldding interface.

The configuration of the substrate/cladding interface has little effect on forging load as shown in Fig. 21, and the simulation of upsetting for a clad billet with a wavy substrate/cladding interface takes more time. If only the prediction of forging load is required, there is no need to consider the configuration of the substrate/cladding interface.

Similarly to the slab method, other effective parameters such as cladding thickness, friction coefficient and temperature have a great effect on forging load. Besides, the heat exchange coefficient also impacts forging load, affecting mainly Zone-III, although the effect is quite slight.

Fig. 22 presents a comparison between experimental and simulated curves obtained by the finite element method and the slab
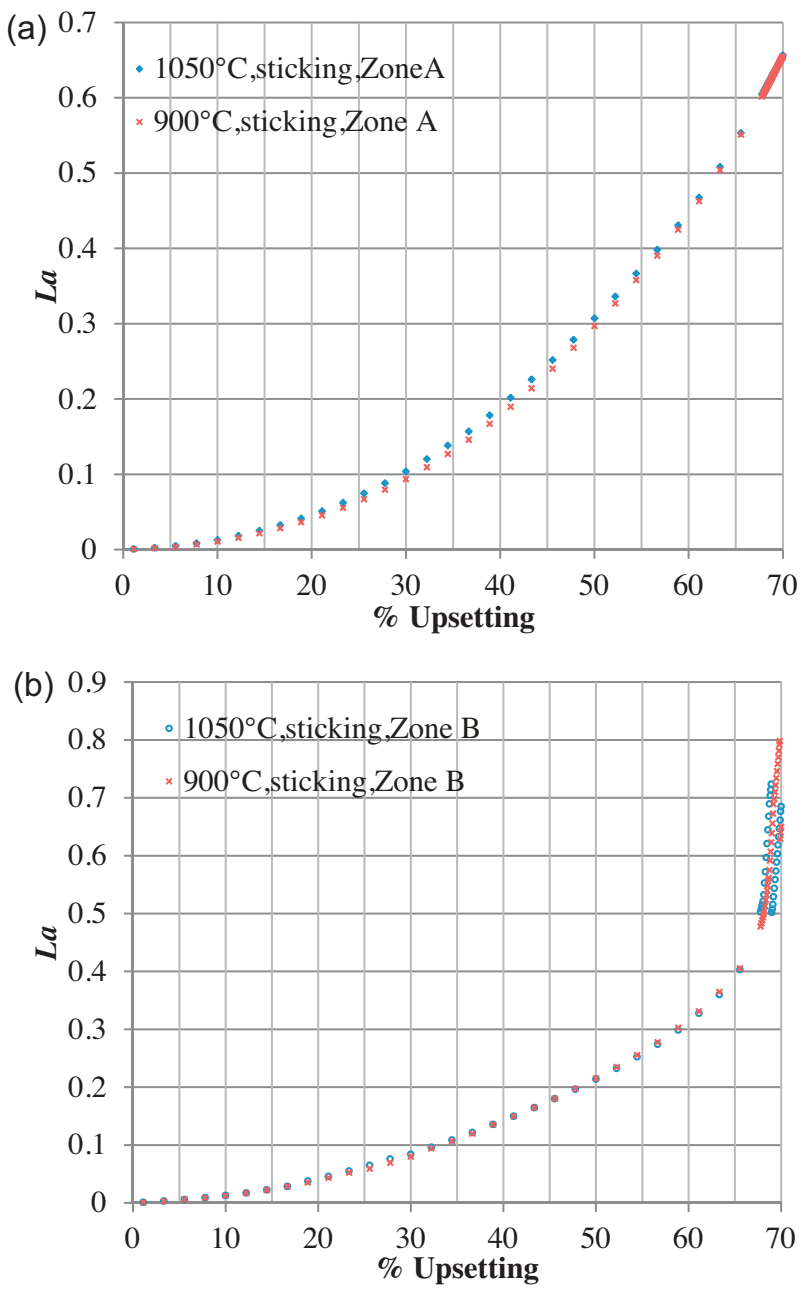

Fig. 20. Effect of temperature on $L a(a)$ Zone A and (b) Zone B.

method using different friction conditions and temperatures. One can note that the experimental load in Zone-II (See Fig. 14) is higher than that of the simulation obtained by the finite element method or the slab method. This feature is notable for each experimental test, the difference appearing more important at lower temperature.

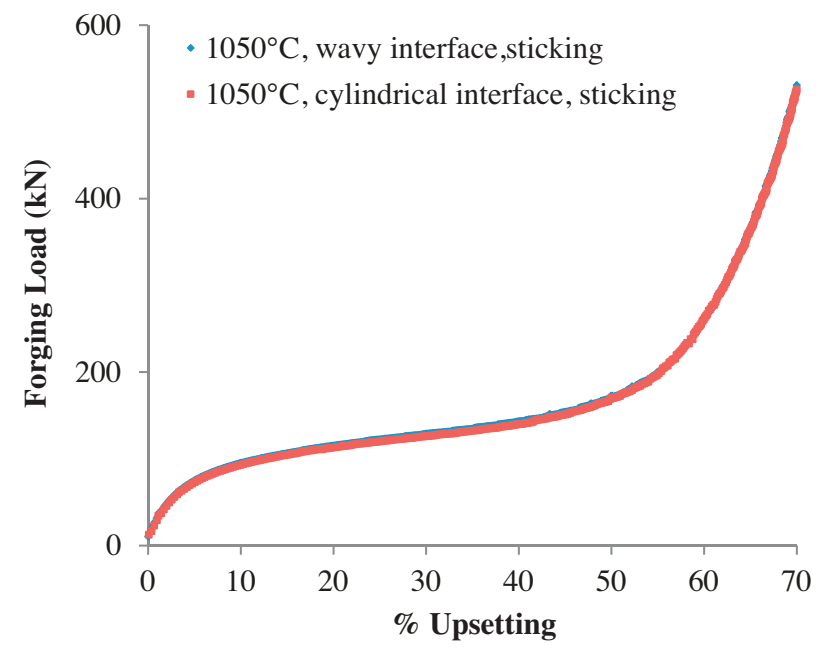

Fig. 21. Simulated forging load obtained with different configurations of the substrate/cladding interface at $1050^{\circ} \mathrm{C}$, sticking friction at die/billet interface. 

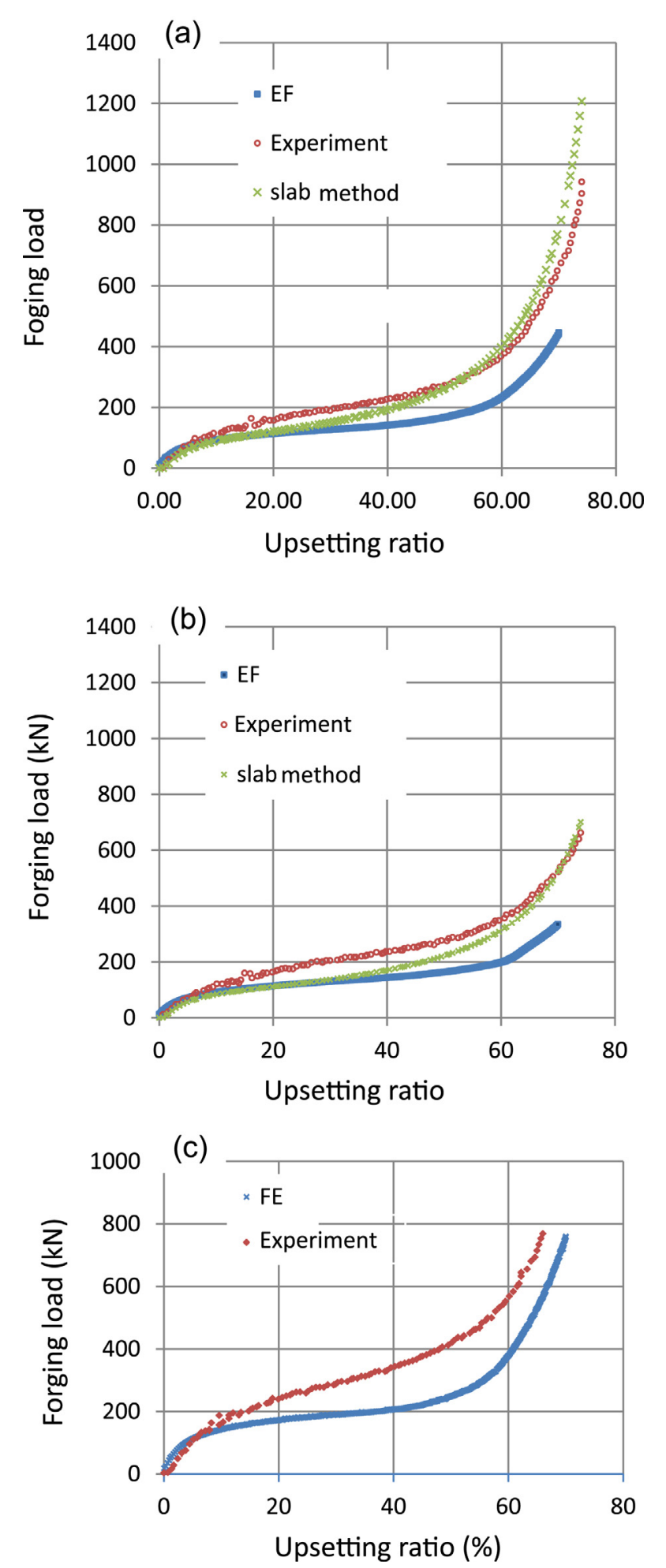

Fig. 22. Forging load versus upsetting ratio obtained experimentally, by finite element simulation and by slab method (a) smooth dry die $(m=0.5), 1050^{\circ} \mathrm{C}$, (b) smooth lubricated die $(m=0.3), 1050^{\circ} \mathrm{C}$ and (c) striated die (sticking), $900^{\circ} \mathrm{C}$.

This difference cannot be due to the implementation of a too low friction coefficient because the effect of friction is noticeable at the end of the upsetting (Zone-III of the curve). However, the Spittel law parameters for the behavior of the clad layer in the finite element model or the slab method is that of SS316L in the FORGE2011 ${ }^{\circledR}$ database. The chemical composition of the clad layer is different from that of filler material because of the dilution of the substrate occurring during fusion weld cladding. The chemical composition and the initial metallurgical structure of the clad billet are different from that of a rolled bar of SS316L because of dilution and due to the fact that the clad layer is obtained by solidification. Furthermore, during the transfer of the billet from the furnace to the dies, thermal exchange between the clad billet and its environment can lead to the cooling of the clad layer. As shown on Fig. 15, the effect of temperature and flow stress of the cladded material is noticeable in Zone-II of the forming curve. This cooling can be taken into account in the finite element model by introducing at the beginning of the simulation a stage during which there is thermal exchange with the environment but no contact between the die and the billet.

\section{Conclusion}

The research proposes to evaluate the characterization of the forgeability of weld clad billet by upsetting test. The experiments, the finite element simulation and the slab method were developed and compared in terms of ductility limit, material distribution and forging load.

The experimental upsetting tests highlight a specific crack type that limits the global ductility of the bi-material clad billet. This kind of crack is the result of the global mechanical interaction between the substrate and the clad layer. The substrate does not present free surface during the forging process; it is cladded and is in contact with the dies at its top and bottom surfaces. Even if the flow stress of the substrate is lower than that of the clad layer, the increase in hydrostatic pressure within the substrate is able to generate stress in the clad layer leading to elongation and ductile cracking of the clad layer. The occurrence and the location of this specific crack can be predicted by the finite element method using a conventional Latham and Cockcroft criterion. It is not necessary to take into account the wavy morphology of the interface between the clad layer and the substrate to predict this phenomenon numerically.

The material distribution during upsetting can be simulated by the finite element method. In the case of upsetting tests, even when using an approximate behavior law for the clad material, the obtained material distribution corresponds well with that of experiments. Among others, the effect of friction is well reproduced. Even if the finite element method is able to simulate the forging of clad billet with more realistic interface geometry, the wavy morphology seems to have a limited effect on the global material distribution. It can be neglected in order to reduce the duration of the calculation.

The material of the clad layer is a mixture of the filler material and the substrate. The dilution phenomenon can lead to a constitutive material of the clad layer with a hot forming behavior very different from that of the pure filler material. This phenomenon can be responsible for the lack of correspondence between experimental and simulated results concerning the evolution of the forging load. It can be expected to have also great effects on the material distribution in the case of forging using a substrate with free surfaces. The difference of the hot forming behavior between the substrate and the clad layer cannot be observed directly via the upsetting test of a clad billet. Inverse calculation methods have to be applied in order to estimate the coefficient of the behavior law of the clad layer. In order to improve the performance of this method, a first calculation can be performed using the slab method followed by a more precise optimization using the finite element method.

\section{Acknowledgements}

The authors would like to thank Region Lorraine and HEC of Pakistan for their financial support. 


\section{References}

Brown, A., 2005. Weld overlay cladding - the solution to pump corrosion? World Pumps 469, 50-53.

Cao, X., Jahazi, M., Fournier, J., Alain, M., 2008. Optimization of bead spacing during laser cladding of ZE41A-T5 magnesium alloy castings. Journal of Material Processing Technology 205, 322-331.

Davis, J.R., 1993. Hardfacing, weld cladding and dissimilar metal joining, welding, brazing and soldering. ASM Handbook 6, 789-829.

Dieter, G.E., 2005. Evaluation of workability for bulk forming processes. ASM Handbook 14A, 587-614.

Domblesky, J., Kraft, F., Druecke, B., Sims, B., 2006. Welded preforms for forging. Journal of Materials Processing Technology 171, 141-149.
Essa, K., Kacmarcik, I., Hartley, P., Plancak, M., Vilotic, D., 2012. Upsetting of bi-metallic ring billers. Journal of Materials Processing Technology 212, 817-824.

Govardhan, D., Kumar, A.C.S., Murti, K.G.K., Madhusudhan Reddy, G., 2012. Characterization of austenitic stainless steel friction surfaced deposit over low carbon steel. Materials and Design 36, 206-214.

Lin, S.Y., 1995. An investigation of die-work piece interface friction during the upsetting process. Journal of Material Processing Technology 54, 239-248.

Lippold, J.C., Kotecki, D.J., 2005. Welding Metallurgy and Weldability of stainless steels, viii. John Willey \& Sons Inc., Canada, pp. 99-111.

Mochnal, G., 2005. Forging of stainless steels. ASM Handbook 14A, 261-268.

Van Tyne, C.J., 2005. Forging of carbon and alloy steels. ASM Handbook 14A, $241-260$. 